\title{
Activities Encountered by European and Other International Authorities
}

\author{
Ahrens, Andreas; Bessems, Jos; Bruinen de Bruin, Yuri; Connolly, Alison; Fantke, Peter; Gilsenan, \\ Mary; Heinemeyer, Gerhard; Jantunen, Matti; Lahaniatis, Majlinda; Papameletiou, Demosthenes \\ Total number of authors: \\ 17
}

Published in:

The Practice of Consumer Exposure Assessment

Link to article, DOI:

10.1007/978-3-319-96148-4 7

Publication date:

2020

Document Version

Peer reviewed version

Link back to DTU Orbit

Citation (APA):

Ahrens, A., Bessems, J., Bruinen de Bruin, Y., Connolly, A., Fantke, P., Gilsenan, M., Heinemeyer, G., Jantunen, M., Lahaniatis, M., Papameletiou, D., Radomyski, A., Reina,' V., Schlüter, Ü., Sommer, Y., Theobald, A., von Goetz, N., \& Zenié, A. (2020). Activities Encountered by European and Other International Authorities. In The Practice of Consumer Exposure Assessment (pp. 511-565). Springer. https://doi.org/10.1007/978-3-31996148-4 7

\section{General rights}

Copyright and moral rights for the publications made accessible in the public portal are retained by the authors and/or other copyright owners and it is a condition of accessing publications that users recognise and abide by the legal requirements associated with these rights.

- Users may download and print one copy of any publication from the public portal for the purpose of private study or research.

- You may not further distribute the material or use it for any profit-making activity or commercial gain

- You may freely distribute the URL identifying the publication in the public portal 


\title{
Chapter 7 \\ Activities Encountered by European and Other International Authorities
}

\author{
Andreas Ahrens, Jos Bessems, Yuri Bruinen de Bruin, Alison Connolly, \\ Peter Fantke, Mary Gilsenan, Gerhard Heinemeyer, Matti Jantunen, \\ Majlinda Lahaniatis, Demosthenes Papameletiou, Artur Radomyski, \\ Vittorio Reina, Urs Schlüter, Yasmin Sommer, Anne Theobald, Natalie von
} Goetz, and Alexandre Zenié

\begin{abstract}
A. Ahrens
European Chemicals Agency (ECHA), Helsinki, Finland e-mail: Andreas.Ahrens@echa.europa.eu

J. Bessems

VITO Health, Mol, Belgium

ISES-Europe Board, Freiburg, Germany e-mail: Jos.Bessems@ISES-Europe.org

Y. Bruinen de Bruin

European Commission Knowledge Management Service, European Commission Joint Research Centre, Ispra, Italy e-mail: Yuri.Bruinen-de-bruin@ISES-Europe.org
\end{abstract}

A. Connolly

ISES-Europe Board, Freiburg, Germany

National University of Ireland, Galway (NUIG), Ireland

e-mail: Alison.Connolly@ISES-Europe.org

P. Fantke

ISES-Europe Board, Freiburg, Germany

Technical University of Denmark, Lyngby, Denmark

e-mail: Peter.Fanke@ISES-Europe.org

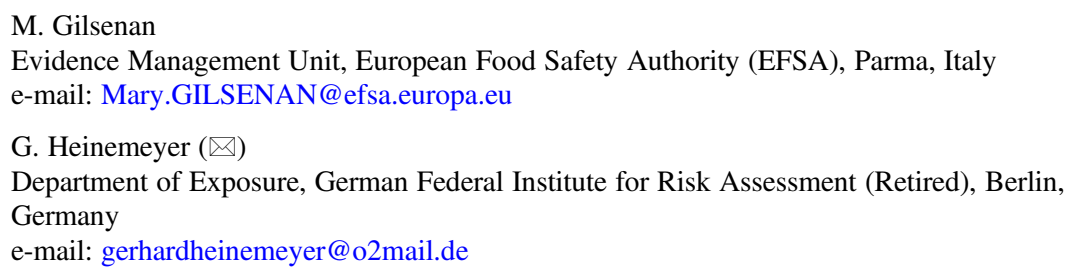

This is a U.S. government work and not under copyright protection in the U.S.; 
The impact of this chapter is to inform the reader of this book about current activities of international bodies to improve the methods used in exposure assessment and the knowledge and information database. In addition the reader shall be given insight into the regulatory work and decision procedures.

\subsection{EFSA}

Mary Gilsenan, Majlinda Lahaniatis, and Anne Theobald

The European Food Safety Authority (EFSA) Parma, Italy is a separate legal entity independent from the European Union (EU) institutions and an integral part of the EU's food safety system (EU 2002). Founded in 2002, EFSA contributes to the safety of the EU food and feed chain and to a high level of protection of human health, mainly by (EFSA 2016a):

- Providing EU risk managers with independent, up-to-date and fit-for-purpose scientific advice on questions related to food and feed safety, animal health and welfare, plant health, nutrition, and environmental issues specific to the above

- Communicating to the public on its scientific outputs and the information on which they are based

M. Jantunen

Department of Environmental Health, National Institute for Health and Welfare (THL) (Retired), Kuopio, Finland

e-mail: matti.jantunen@janding.fi

M. Lahaniatis

International Affairs, German Federal Institute for Risk Assessment, Berlin, Germany

e-mail: Majlinda.Lahaniatis@bfr.bund.de

D. Papameletiou $\cdot$ A. Radomyski $\cdot$ V. Reina $\cdot$ A. Zenié

European Commission, Joint Research Centre (JRC), Ispra, Italy

e-mail: Alexandre.ZENIE@ec.europa.eu

U. Schlüter

ISES-Europe Board, Freiburg, Germany

BAUA, Dortmund, Germany

e-mail: Urs.Schlueter@ISES-Europe.org

Y. Sommer

Department of Exposure, German Federal Institute for Risk Assessment, Berlin, Germany e-mail: yasmin.sommer@bfr.bund.de

A. Theobald

European Food Safety Authority (EFSA), Parma, Italy

e-mail: Anne.Theobald@efsa.europa.eu

N. von Goetz

ISES-Europe Board, Freiburg, Germany

ETH Zurich, Zurich, Switzerland

e-mail: Natalie.von-Goetz@ISES-Europe.org 
- Cooperating with Member States, institutional partners and other interested parties/stakeholders in the EU to promote coherent advice and increase trust in the EU food safety system

- Developing standardised and harmonised methodologies, and collecting and analysing data to allow the identification, characterisation and monitoring of emerging risks that have a direct or indirect impact on food and feed safety.

Only the European Commission (EC), the European Parliament (EP) and the competent authorities in EU Member States (EU MS) are entitled to ask scientific advice from EFSA. Once a request for scientific advice from the above-mentioned actors is accepted by EFSA, it becomes a Mandate, which is assigned to one or more scientific panels or the Scientific Committee depending on the scientific area and the expertise needed.

EFSA's scientific advice is given in form of scientific opinions by one or more of EFSA's 10 scientific panels or its Scientific Committee. The members of the Scientific Committee and the panels are independent experts appointed through an open selection procedure mainly from European universities, public research organisations, national authorities and food safety agencies. EFSA staff may also produce scientific outputs on behalf of the agency, such as peer reviews of the risk assessment of active substances in pesticides, dietary exposure assessments of foodborne substances or responses to urgent requests for scientific advice. EFSA staff also monitors and analyses information and data on biological hazards, contaminants, veterinary drug residues, and emerging risks.

EFSA's panels and Scientific Committee also carry out scientific work on their own initiative. This is known as 'self-tasking' and mainly applied to examine emerging issues and new hazards, and to update its risk assessment methods and approaches.

The EFSA's scientific process 'is composed of three steps: receipt of request, risk assessment and adoption of the opinion. In the risk assessment phase, the panel or the Scientific Committee sets up a Working Group of experts, which undertakes detailed scientific work based on scientific evidence (data and literature) and expertise. The Working Groups generally develop draft opinions and submit them to the panel for discussion and possible adoption. EFSA often holds public consultations on its draft opinions and guidance documents. The Scientific Committee or panel reviews the feedback received to draft the final opinion, which is adopted by a majority of their members with a quorum of at least two thirds of members present. The EFSA opinions are published in the EFSA Journal, which is an open-access, online scientific journal. The Authority is legally bound by European Union legislation on issues such as public access to documents (EU 2001).

EFSA adheres to a number of principles and practices aimed at ensuring the excellence of its scientific work. Transparency (access to documents) and openness (engagement) have been key values for EFSA since its creation. Adherence to these

\footnotetext{
${ }^{1}$ EFSA's scientific process. A step-by-step guide. Available at: http://www.efsa.europa.eu/interac tive_pages/scientificprocess/ScientificProcess
} 
values helps to legitimise EFSA's work and ensure accountability to society. In EFSA's context, openness and transparency allow civil society to be informed about EFSA's internal processes, have access to and understand its outputs, and engage in EFSA's scientific decision-making process in the appropriate consultative fora. The Open EFSA initiative, ${ }^{2}$ launched in 2014 , and the subsequent TERA project (Transparency and Engagement in Risk Assessment) aim at exploring and implementing several measures for enhancing transparency and engagement in EFSA's risk assessment workflow. With the entry into force of the so-called 'Transparency Regulation' (EU 2019), EFSA has a legal mandate for several tasks related to data management, e.g. submission of data in structured format which might have also an implication on future ways of engaging with the public and performing exposure and risk assessment.

Additional activities are undertaken by EFSA to further develop its risk assessments and align its methodologies with the latest developments in science. The collection, appraisal and analysis of evidence - data, literature and expert judgement - are key steps in preparing EFSA's scientific risk assessments. In the frame of the PROMETHEUS project (PROmoting METHods for Evidence Use in Scientific Risk assessments), EFSA developed new methods and approaches ${ }^{3}$ for impartiality, methodological rigour, transparency and responsiveness when using scientific evidence (i.e. selecting, appraising and integrating evidence in scientific risk assessments). The new methodological framework for the use of evidence can also be applied by risk assessors across Europe and beyond. It involves a four-step process to achieve fit-for-purpose, evidence-based scientific advice for decision-makers:

- Plan (i.e. planning a strategy for the risk assessment upfront).

- Conduct (i.e. carrying out the assessment as far as possible in line with the strategy). In this context, data are selected, appraised and integrated according to predefined criteria, and methods are tailored to the objectives and context of the assessment.

- Verify (i.e. corroborating the assessment process with the strategy).

- Report (i.e. documenting and explaining the process, results and conclusions and ensuring accessibility of methods and data).

EFSA seeks to develop further guidance, recommendations, and processes to keep pace with international scientific developments and regulatory science needs. ${ }^{4}$ For example, EFSA's Scientific Committee has developed draft guidance on how to assess uncertainty in a structured and systematic way with the aim to offer a toolbox of methodologies, both quantitative and qualitative, and related training (EFSA

\footnotetext{
${ }^{2}$ EFSA 2014. Discussion Paper Transformation to an 'Open EFSA' http://www.efsa.europa.eu/en/ corporate/doc/openefsadiscussionpaper14.pdf

${ }^{3}$ Methods for evidence use in scientific assessments. Furthering impartiality, methodological rigour, transparency and responsiveness when using evidence. Available at: https://www.efsa.europa.eu/ interactive_pages/prometheus/prometheus
}

${ }^{4}$ EFSA Guidance and assessment approaches (https://www.efsa.europa.eu/en/methodology/ guidance) 
2018). In 2016, EFSA's Scientific panels started to trial the Revised draft Guidance on Uncertainty in Scientific Risk assessment in at least one of their scientific risk assessments. Other guidance documents relate to biological relevance and on weight of evidence pertaining to its scientific assessments (EFSA 2017a).

EFSA has also developed Guidance on expert knowledge elicitation (EFSA 2014f) to be used in cases of limited empirical evidence for a risk assessment and where expert judgment in the areas covered by EFSA's remit is needed. The Guidance provides detailed protocols and establishes a phased process with assigned responsibilities at each step: defining the risk assessment problem, preparing for elicitation, and conducting an expert elicitation, culminating in complete documentation.

In order to continually monitor and improve the quality of its scientific work, EFSA has developed a robust quality management system (QMS) that includes selfreview and customer feedback systems. It ensures that scientific processes are developed consistently and continuously improved across EFSA's panels and by staff. $^{5}$ In November 2016, EFSA obtained the ISO9001: 2015 certification attesting that its QMS is considered robust, well established and in compliance with international recognised standards.

EFSA estimates dietary exposure in two main areas: regulated products and contaminants.

- Regulated products: Includes substances intentionally added to and/or used on food and feed such as additives, enzymes, flavourings, and nutrient sources and other substances/products such as food contact materials, pesticides, genetically modified organisms, novel foods, food-related processes and processing aids.

- Contaminants in food and feed: EFSA also carries out risk assessments on a wide range of contaminants that can be present in food and feed due to food production, distribution, packaging or consumption, as well as those that might be present in the environment naturally or as a result of man-made activity.

The provision of European data and exposure assessments is important as many food products are regulated at the European level, hence calling for a European approach in exposure assessment. The challenge is to provide risk managers with assessments of exposure and risk that enable to establish maximum limits, indicative values for contaminants, or to establish limits for other food-borne hazards. These values should ideally be conservative enough to protect the population with the highest expected exposure taking into account consumption patterns and occurrence data for the respective hazard.

In general dietary exposure is calculated for each European country using consumption data from the EFSA comprehensive database (see Sect. 6.3.1) combined with levels of e.g. food-borne hazards or nutrients. In order to be protective, usually a high percentile of exposure (e.g. the 95th percentile) is used in risk assessments. Dietary exposure for subpopulations such as infants is calculated separately for specific requests.

\footnotetext{
${ }^{5}$ How we work. Available at: https://www.efsa.europa.eu/en/about/howwework
} 


\subsubsection{EFSA Databases and Data Collection}

In the late 1990s-early 2000s, European legislators identified the lack of an effective system of collection and analysis of data on the food supply chain at the European Community level as a major shortcoming. Therefore, it proposed in EFSA's Founding Regulation (EU 2002) that one of EFSA's tasks is to search for, collect, collate, analyse and summarise relevant scientific and technical data within its remit. This involves, in particular, the collection of data relating to: (a) food consumption and the exposure of individuals to hazards related to the consumption of food; (b) incidence and prevalence of biological risk; (c) contaminants in food and feed; (d) residues.

For the purpose of collecting data on occurrence of food-borne chemical hazards, as well as food consumption, EFSA relies on competent authorities in EU Member States, the food industry, academia, and research organisations. To reinforce this task, EFSA manages data Networks (with data provider representatives from European countries), e.g. on Chemical Occurrence Data, Pesticides Residues and on Food Consumption Data, to discuss data needs and common standards to transmit the data to EFSA, to provide training on data transmission requirements, and to share experiences and best practice. The minutes of the data network meetings are published on EFSA's website. ${ }^{6}$ EFSA also engages with industry and other stakeholders to collect food additive and contaminant data for its dietary exposure assessments. ${ }^{7}$ An extensive description of methods to collect and generate reliable data on concentrations of substances in food is given in Sect. 4.8. These data collections are mainly conducted at the national level.

EFSA created its Comprehensive European Food Consumption Database in 2010 from existing national information on food consumption at individual level. Competent organisations in European countries provided EFSA with data from the most recent national dietary surveys in their country. Survey results for children were mainly obtained through the EFSA Article 36 project 'Individual food consumption data and exposure assessment studies for children' (EXPOCHI) through the consortium (EFSA 2011). EFSA uses its food classification system 'FoodEx' (see Sect. 4.4.1) to categorise all foods and beverages included in the Comprehensive Database. Since 2012, all food consumption data submissions to EFSA have been reported in accordance with FoodEx 2 food classification and description system that enables more precise reporting of consumption patterns. The database includes individual dietary records from some 100,000 subjects (infants to elderly) out of more than 510 million inhabitants in 23 out of 28 EU Member States (status: April 2017). The summary statistics are published in EFSA's scientific data warehouse.

\footnotetext{
${ }^{6}$ EFSA's Data collection and analysis networks https://www.efsa.europa.eu/en/data/networks ${ }^{7}$ EFSA stakeholder discussion group on food chemical occurrence data https://www.efsa.europa.eu/ en/engage/stakeholders
} 
EFSA and the national data providers of the comprehensive database have agreed on the use of the data. EFSA has the right to make use of the raw individual food consumption data for carrying out risk assessments and other scientific analyses within the activities related to EFSA's mandate. A formal authorisation from the data provider must be requested for any other use of the data in order to make the data also useful for the wider public including applicants (EFSA 2011).

One of the limitations of the comprehensive database is that due to the different methodologies used to collect data at national level, country-to-country comparisons of exposure estimates should be interpreted with caution. In 2011, EFSA launched its EU Menu project that aims to provide more standardised and higher quality data on food consumption using FoodEx 2 food classification and description across the EU, according to the EU Menu methodology (EFSA 2014b). EFSA provides guidance as well as financial support to participating countries. Some 30 surveys covering different population groups (e.g. children and adults) are ongoing in the EU Menu project.

EFSA aims to gradually update its Comprehensive database with national surveys conducted according to the EU Menu project methodology.

On an international level, EFSA collaborates with the WHO (World Health Organisation) and the FAO (Food and Agricultural Organisation of the United Nations) to support efforts to harmonize food consumption data in the Codex region. In particular, EFSA provides support to extend the use of FoodEx2 food classification to cover food consumption preferences outside of Europe, in the context of the FAO/WHO Global Individual Food Consumption Data Tool (FAO/WHO GIFT). ${ }^{8}$ Summary statistics from the EFSA comprehensive database have also been included in the FAO/WHO Chronic Individual Food Consumption Database - summary statistics (CIFOCOss) ${ }^{9}$ hosted by the WHO.

\section{Chemical Occurrence Databases}

EFSA collects some one million analytical records on contaminants and food additives annually from data providers (public and private) in European countries through calls for data, ${ }^{10}$ as well as some 20 million analytical results on pesticide residues in food. The majority of the data are from monitoring programmes. In order to standardise data on contaminants and pesticide residues transmitted to EFSA and to improve the data quality, EFSA developed the Standard Sample Description (SSD) (EFSA 2010a, 2013) in collaboration with Member States, which is the EFSA standard for transmission of analytical occurrence data to EFSA.

\footnotetext{
${ }^{8}$ FAO/WHO Global Individual Food consumption data Tool (FAO/WHO GIFT) http://www.fao. org/nutrition/assessment/food-consumption-database/en/

${ }^{9} \mathrm{The}$ FAO/WHO Chronic individual food consumption database - Summary statistics (CIFOCOss) http://www.who.int/foodsafety/databases/en/

${ }^{10}$ EFSA's calls for data https://www.efsa.europa.eu/en/calls/data
} 
The SSD data model contains approximately 80 standardised data elements (fields) that describe the characteristics of an analytical sample and result (e.g. laboratory sample code, analytical method, limit of detection of the analytical method, country of origin, etc.), of which approximately 20 are mandatory. In addition, it contains controlled terminologies (e.g. standard lists of analytical methods, names of chemicals, etc.) and business (validation) rules (e.g. whether data pertaining to data elements have been submitted in the required format) to ensure baseline data quality. The IT protocol to transmit data to EFSA using the SSD standard data model is described in a complementary guidance document, Guidance on Data Exchange (EFSA 2014c).

Data providers transmit data through the EFSA Data Collection Framework (DCF) web-based interface that provides functionalities of automatic validation of the incoming data. The system automatically checks for the correct completion of mandatory fields and compliance with business rules, after which data providers receive automatic feedback. After an ETL (Extract, Transform, Load) procedure, data are stored in EFSA's scientific data warehouse and later extracted for use in dietary exposure assessments. Data stored in EFSA's scientific data warehouse are publically accessible via EFSA's website at different levels of aggregation to third parties according to EFSA's data warehouse access rules (EFSA 2015a). An overview of data providers is also provided. ${ }^{11}$

Since 2007, EFSA awarded some 4 million euros to Member States organisations involved in data collection to support data standardisation at the European level as well as electronic transmission of data to EFSA across the following domains: zoonoses, contaminants, food additives, pesticides residues and veterinary drug residues.

The added value for Member State data providers is that occurrence data from several food safety domains can be reported to EFSA in a standardised format. Consequently, the SSD is becoming the accepted European standard for describing and reporting monitoring results for food-borne hazards. An additional benefit at the national level is that Member States accumulate a large volume of data from their national control and monitoring activities in a harmonised format that can also be used to support risk assessment activities at national level.

To avoid duplication of effort by European data providers, EFSA transmits contaminant oceurrence data to the WHO GEMS/Food (Global Environment Monitoring System) for use in risk assessments of the joint FAO/WHO Expert Committee on Food Additives (JECFA).

As EFSA's SSD data model and the WHO GEMS/Food model to receive data for risk assessment purposes are not entirely aligned, some adaptation of EFSA data from SSD to GEMS/Food was required to transmit raw data from EFSA to WHO. In 2014, EFSA compared the two models and provided technical information regarding the transmission of contaminant occurrence data from the EFSA database into the electronic data submission system of WHO (EFSA 2015b).

\footnotetext{
${ }^{11}$ EFSA's data collection, standardisation and analysis https://www.efsa.europa.eu/en/science/data
} 


\subsubsection{EFSA's Approaches to Dietary Exposure Assessment of Regulated Products and Contaminants}

This chapter briefly describes the principles of dietary exposure assessment applied by EFSA for regulated products and contaminants and gives some examples of exposure assessment approaches. In general, EFSA provides guidance to applicants/ industry on the kind of scientific data and information needed to perform a risk assessment. These guidance documents include advice on how exposure shall be calculated. ${ }^{12}$ It should however be borne in mind that science evolves and better/ more precise data and methodologies may become available. In this case the EFSA guidance documents are updated and published.

The exposure estimates are performed by the working groups of the respective scientific panels and/or by EFSA staff. The panels are responsible for and officially adopt the final risk assessments, including the underlying exposures assessments.

\section{Food Additives}

EFSA has developed a screening tool for estimating long-term exposure to food additives. This is the Food Additives Intake Model (FAIM) (EFSA 2014a, see also Sect. 4.17). It allows applicants and EFSA experts to estimate mean and high exposure to food additives for different population groups throughout several European countries using the summary statistics from EFSA's Comprehensive Database.

In the case of an application for a new food additive or an extension of use for an already approved food additive, the applicant is requested to provide information on the proposed uses and use levels in foods in the data package submitted for the safety evaluation to EFSA (2012b). This information can be inserted in FAIM to estimate dietary exposure.

In the context of the re-evaluation programme for food additives permitted for use before 2009 and currently on the EU market, a stepwise approach to estimating exposure is followed. Specific maximum permitted levels (MPLs) have been established for most food additives in the respective EU legislation. Some of them can, however, be used according to the quantum satis (QS) principle - at the lowest level necessary to achieve the desired technological effect. In a first step exposure is estimated by combining these MPLs with the food consumption data. This may result in a very conservative exposure scenario because it assumes that an individual is eating all the foodstuffs that can contain a given food additive at its MPL. Such overestimation often leads to exceedance of the ADI (Acceptable Daily Intake) for the respective food additive. In order to obtain more realistic use data EFSA regularly publishes calls for data ${ }^{13}$ for each food additive under re-evaluation to

\footnotetext{
${ }^{12}$ Submitting an application to EFSA: http://www.efsa.europa.eu/en/applications/about/submitting

${ }^{13}$ EFSA's calls for data https://www.efsa.europa.eu/en/calls/data
} 
get information from interested business operators (e.g. food industry) to support the exposure assessments. Typical use levels from industry together with analytical data provided by the Member State competent authorities are combined with the food consumption data from the EFSA comprehensive database to estimate a more refined exposure scenario.

\section{Flavourings}

Chemically defined flavouring substances were assessed for previous risk assessments via flavouring group evaluations (FGEs) within the so-called 'Procedure'. Dietary exposure was based on: (1) poundage data (production volumes of a flavouring) reported by industry using the Maximised Survey-Derived Daily Intake (MSDI) method and (2) a combination of standard portion sizes with rough usage levels reported by industry using the modified Theoretical Added Maximum Daily Intake (mTAMDI) method. Both methods suffer from limitations such as the yearto-year variability in production volumes, the underreporting correction factor and the assumed percentage of consumers. Whereas the MSDI model tends to underestimate the intake of a flavouring substance for certain groups of consumers, the mTAMDI is regarded as a conservative estimate because it is based on the assumption that the consumer regularly eats and drinks several food products containing the same flavouring substance. However, with the modification to consider the normal instead of the upper reported use levels, it is less conservative than the TAMDI. As a consequence, there have been differences of several orders of magnitude in results between mTAMDI and MSDI for some of the FGEs (Arcella and Leclercq 2005). The mTAMDI value was only used as a tool to screen and prioritise the flavouring substances according to the need for refined intake data and was not considered in the 'Procedure'.

The CEF Panel has subsequently established a new exposure approach called Added Portions Exposure Technique (APET) method in its guidance document from 2010 (EFSA 2010b) which is applicable to all new flavourings, both chemically defined and other flavourings for which an evaluation and authorisation after 2010 has been sought. This methodology accommodates the need for harmonised exposure estimation with existing exposure assessment procedures for flavourings such as the Single Portion Exposure Technique (SPET) used by JECFA. The APET method is an adaptation of the TAMDI method with the main difference being use of standard portions established for each food category. Short-term exposure was in the past and is also now addressed. Novelties of the method are the estimation of the potential cumulative dietary exposure by taking into account the intake of structurally and metabolically related substances, the consideration of natural occurrence in processed and non-processed foods, as well as exposure from non-food sources. Specific scenarios are calculated for children in order to attribute their higher food consumption with respect to body weight. 


\section{Smoke Flavourings}

Smoke flavourings are both legally and from a scientific point of view considered different from flavourings. They are mixtures of many chemical compounds and their anticipated uses as well as the use levels differ from those proposed for chemically defined flavouring substances. Therefore, as no specific methodology for the estimation of dietary exposure to Smoke Flavourings existed, the CEF Panel decided to test existing methodologies and develop new methodologies for this special type of flavourings. The details are described in the CEF opinion on Dietary exposure assessment methods for smoke flavouring Primary Products (EFSA 2009a).

The Smoke Flavouring Theoretical Added Maximum Daily Intake (SMK-TAMDI) assumes that the hypothetical consumer will consume a fixed amount of flavoured solid foods and liquids daily. The unique approach here is that a single group 'Beverages' is used for liquids whereas solid foods are divided in 'traditionally smoked solid foods' and 'other solid foods not traditionally smoked'.

The Smoke Flavouring EPIC (SMK-EPIC) model makes use of the information on the consumption of smoked foods available from the European Prospective Investigation into Cancer and Nutrition (EPIC) study. This study is one of the few cases in which the consumption levels of 'smoked meat' were assessed for different European countries. It is based on assumptions that a hypothetical high-level consumer of smoked meat is also an average consumer of the other traditionally smoked foods and an occasional consumer of smoked foods or beverages from each of the other categories.

To date the CEF Panel has evaluated 11-smoke flavourings and based its exposure assessments on Upper Use Levels as provided by the applicants, using the SMK-TAMDI and SMK-EPIC methods. The highest value among these exposure estimates was used when carrying out risk assessments to these products.

\section{Food Enzymes}

The CEF Panel had suggested in its guidance (EFSA 2009b) that a conservative method such as the 'Budget method' should be used to estimate potential human exposure to food enzymes and any other constituents or by-products of concern. The panel has taken note when applying the methodology that enzymes are added during processing of food and food ingredients.

Based on the initial experience the CEF Panel has proposed a tiered approach in line with the EFSA advice to use 'a stepwise or tiered approach in which the initial steps rely on conservative screening methods'. Instead the panel recommends the use of actual food consumption data reported in the EFSA comprehensive food consumption database, and recommends the development of a food process-based tool, based on summary statistics (EFSA 2016b). 


\section{Food Contact Materials}

In contrast to chemicals that are directly added to and are present (intentionally or not) in food, starting materials or additives of plastic materials can unintentionally end up in food by migration. The magnitude of the potential so-called specific migration depends on a multitude of factors such as the nature of the packaging material, the nature of the food (e.g. dry, acid, fatty, or liquid), and the temperature and time of contact of the plastic material with food. Actual occurrence data of chemicals derived from food contact materials are very scarce as it is very cumbersome and resource intensive to measure these chemicals in a multitude of different complex food types. Therefore, several approaches have been taken to provide data on migration as a basis for occurrence data. It is assumed that the food contact material releases a substance into a food at the highest concentration level measured either in food simulants (for aqueous, fatty, alcoholic or acid food types), or calculated using worst-case scenarios (i.e. total mass transfer) or mathematical migration modelling. Dietary exposure to food contact materials is estimated on the basis of a model diet, which assumes that a person weighing $60 \mathrm{~kg}$ may consume $1 \mathrm{~kg}$ daily of food (including beverages) that is in contact with $6 \mathrm{dm}^{2}$ (surface of a $10 \mathrm{~cm}^{3}$ ) of food contact material containing the chemical under assessment. For fatty foods, which are important for the migration of highly polar organic substances, it is assumed that a person consumes only up to $200 \mathrm{~g}$ of fat daily (Fat reduction factor).

Such an approach is necessary as in the past knowledge of the type of packaging for the different foodstuffs was neither systematically available nor collected. The EFSA comprehensive database, however, contains some national surveys for which more general information on the type of packaging is available. EFSA has also updated its FoodEx 2 format in order to incorporate a facet for food packaging that will allow a better estimation of exposure from certain food contact materials. The issue is not trivial if one imagines that the final food (and its ingredients) may have been in contact during manufacture, storage, transport, etc., several times and with several different packaging materials. Also refined models will not be able to deal with such complex scenarios.

The CEF Panel has started to revise its guidance on food contact materials and identified, as one major area to revisit, the estimation of consumer exposure. The standard value of $6 \mathrm{dm}^{2} / \mathrm{kg}$ is appropriate to represent the surface to mass ratio of packaged foodstuffs based on consideration of several scientific publications where surface to volume of packed food was analysed. The Panel had different suggestions to replace the standard value with more refined scenarios. This proposal will provide the European Commission (EC) with the scientific basis for a discussion among risk managers on possible implications for risk management. It is intended that the European Commission will provide feedback to EFSA to prepare updated guidelines for data requirements (including exposure assessment) for the safety assessment of a substance to be used in food contact materials (EFSA 2016c). 


\section{Feed Additives}

Feed additives may end up in the human diet indirectly through the consumption of tissue from mammals, birds or farmed fish, and via products, such as milk and eggs. The estimation of dietary exposure considers the additives (expressed as total relevant residues) in combination with a model diet for humans using default values for daily food consumption based on worst-case scenarios, e.g. daily consumption of $100 \mathrm{~g}$ of liver from mammals and/or birds (EFSA 2012a).

EFSA has recently published the Guidance for public consultation on the assessment of the safety of feed additives (EFSA 2017b). It proposes use of consumption data of edible tissues and products as derived from the EFSA Comprehensive European Food Consumption Database to assess exposure to residues from the use of feed additives in different EU countries, age classes and special population groups. A web-based tool will be made available by EFSA, supporting assessors in the calculation of long- and short-term exposure estimates according to the above methodology.

\section{Genetically Modified (GMs) Foods}

In the European Union (EU), foods derived from genetically modified organisms (GMOs) are subjected to a risk assessment before authorisation. Dietary exposure is one essential element of the risk assessment of GM foods.

Commission Implementing Regulation (EU) No. 503/2013 (EU 2013) requests that the anticipated dietary intake of genetically modified (GM) food is estimated by an applicant on the basis of representative consumption data, and that it should consider also particular consumer groups. Data on import and production quantities may provide additional information for the intake assessment.

A crude estimate of dietary exposure is used during hazard identification and characterisation to support the choice of dose regimes. If a hazard is identified, then a more refined dietary exposure is necessary to determine the associated risk. A refined exposure assessment is also needed to assess the consequences of consumption of GM foods with altered nutritional profiles. The exposure of a hazardous substance is based on estimates of the observed consumption of all foods that may contain that substance, preferably in representative samples of the population. This is followed by multiplication of the amounts of food consumed by the known or predicted concentrations of the substance in each food, to arrive at the total daily exposure to that substance by members of a defined population group. These data are then compared with toxicological data to assess risk. The outcome of the compositional analysis decides whether a detailed nutritional assessment is required for specific nutrient(s). The nutritional assessment of GM foods is intended to demonstrate that the GM food is not nutritionally disadvantageous to humans. This can be as a consequence of new constituents, or constituents that occur naturally in the concerned crop but at altered levels as a consequence of the genetic modification. 


\section{Novel Foods}

Long-term dietary exposure is typically assessed for novel foods. Food consumption data from the literature (e.g. figures published from national dietary surveys) are multiplied by maximum intended use levels of the novel food and food ingredient to estimate dietary exposure. In practice, food consumption data from one Member State (e.g. UK National Diet and Nutrition Survey) is mainly used as it is open data. When necessary, EFSA validates applicants' exposure assessments submitted in the frame of an application by using data from the comprehensive database. The FAIM tool may be used by applicants for the intake assessment of novel foods used as ingredients where the food categories to which the ingredient is intended to be added match reasonably well the food categories included in the FAIM tool. It may be sufficient for the intake assessment if the resulting high percentile intakes of the concerned population groups are below the levels that may pose safety concern. In cases where more refined estimates are needed, the applicant may consider more detailed assessments (EFSA 2016d).

\section{Nutrients Sources Added to Food}

Applicants estimate the dietary exposure to nutrients added to food by summing the highest reported nutrient use level (per day) with average and high (based on the 95th or 97.5th percentile) dietary intakes derived from the scientific literature. Estimates are calculated for adults and children.

\section{Other Substances Added to Food (e.g. Botanicals)}

Dietary exposure to other substances added to food (e.g. botanicals and isoflavones) is estimated on a case-by-case basis. EFSA supports the ANS Panel working group on botanicals in food regarding ad hoc data collection on food supplement composition and use patterns. This information is usually complemented by a summary of the relevant literature and used for the exposure assessment.

\section{Pesticides}

While risk assessments and authorisation for active substances were harmonised in the early 1990s at the European level with the now repealed Council Directive 91/414/EEC (EU 1991), safety assessments and approvals of plant protection products (also referred to as 'pesticides') containing active substance(s) are still within the remit of the European Member States, albeit respecting the harmonised assessment principles for plant protection products established in Regulation (EC) No. 1107/2009 (EU 2009). 
Within the risk assessments for humans, exposure to active substances is assessed not only via diet, but also for operators, workers, residents and bystanders exposed via other routes, e.g. dermal and inhalative (EFSA 2014d). It is a major objective of the editors of this book to address the impact of assessing the total exposure accumulated from all sources combined. This issue is particularly addressed in various chapters (Sects. 3.2, 3.5 and 3.6 (consumer exposure exposome)). This kind of exposure assessment has been addressed in Sect. 7.8 and here the focus will be on dietary exposure assessment.

In the context of risk assessment, prospective assessments for short- and longterm exposure are performed for many kinds of applications (new products, amendment of uses and renewal of authorisation) of active substances. For this purpose, EFSA developed a calculation model, PRIMo (Pesticide Residue Intake Model) that is based on national food consumption figures and unit weights provided by Member States and implements internationally agreed risk assessment methodologies. Revision 2 of the model allows users to perform the risk assessment in accordance with the internationally agreed methodologies, with some specific European deviations regarding the variability factors for acute risk assessment. ${ }^{14}$ PRIMo revision 2 can also be used as a first 'screening tool' based on conservative assumptions using MRL values (EFSA 2007). If no consumer risk is identified with the screening methodology, it is not necessary to use more sophisticated calculation tools. For 'refined calculations', the MRLs can be replaced by other values such as Supervised Trials Median Residue (STMRs). Further refinements for the specific active substance include Highest Residue (HR-values) obtained from field trials or monitoring programmes and the consideration of processing factors.

As requested in Regulation (EC) No. 396/2005 (EU 2005), EFSA also prepares annual reports ${ }^{15}$ on pesticide residues from the official control activities for food and feed carried out by the European Member States, Iceland and Norway. In addition to the analysis of MRL compliance, EFSA carries out short- and long-term dietary exposure assessments based on the actual monitoring data using the deterministic screening tool PRIMo. Through this screening EFSA estimates the exposure of European consumers to pesticide residues. Taking into account the recommendations presented in the report on pesticide residues, the European Commission, in its risk manager role, takes appropriate risk management actions, complementing the risk management actions implemented at the approval of a pesticide.

According to Regulation (EC) No. 1107/2009 (EU 2009), the known cumulative and synergistic effects shall be taken into account in the risk assessment. EFSA has proposed methodologies to address the potential effects from combined exposure to pesticides that share similar toxicological properties. The PPR Panel has adopted four scientific opinions and one guidance document on the use of a probabilistic

\footnotetext{
${ }^{14}$ PRIMo - Pesticide Residue Intake Model. http://www.efsa.europa.eu/applications/pesticides/ tools

${ }^{15}$ European Union reports on pesticide residues. http://www.efsa.europa.eu/en/publications/ advanced-search/?sub_subject $=70065$
} 
methodology for modelling cumulative dietary exposure to pesticide residues in order to develop and apply a science-based methodology in this area. In its 2010 annual report on pesticide residues in food, EFSA has for the first time estimated the combined exposure for two groups of pesticides on the basis of monitoring data provided by all Member States (EFSA 2010c). Since the work on the establishment of cumulative assessment groups (CAGs) and the assessment methodology had not yet been finalised, this exercise was aimed to testing of the suitability of the monitoring data for this type of assessment. The PPR Panel also tested the cumulative risk assessment using selected pesticides from the Triazole Group. The scientific opinion describes the progressive steps of refinement in cumulative risk assessment. The refinement of the cumulative exposure assessment making use of deterministic and probabilistic methodologies in successive tiers is one part. The most important step in applying this methodology will however be the development of the cumulative assessment groups, which is still in progress. The development of tools to perform cumulative exposure calculations according to the methodology proposed by the PPR Panel was also covered by a project funded by the European Commission (ACROPOLIS project) using MCRA (Monte Carlo Risk Assessment) software.

\section{Contaminants}

Daily dietary intakes (average and high levels) of contaminants in food for the total population are estimated by combining individual food consumption data from the EFSA Comprehensive Food Consumption Database with contaminant occurrence data mainly from national monitoring and surveillance programmes. Data on contaminant occurrence in food are matched with the related consumption data using the FoodEx food classification. In the absence of monitoring data from Member States, literature data are typically used when available. Long-term dietary exposure is typically assessed and, when a toxicological evaluation indicates a need, acute dietary exposure is estimated by means of deterministic or probabilistic methods. Since 2010, all dietary exposure estimates in this area are carried out using the Comprehensive Database and Contaminant Occurrence Database.

\section{Specific Examples}

Aggregate exposure [exposure to a single chemical via all exposure routes (e.g. dermal, oral, and inhalation) and from different sources] has not been widely applied in EFSA Panel opinions to date. Two recent examples include the CEF Panel opinion on BPA (Bisphenol A) (EFSA 2015b) and the Scientific Committee opinion on Carvone (EFSA 2014e). The former included an estimate of combined exposure from the diet, drinking water, inhalation, as well as dermal contact to cosmetics and thermal paper; the latter included an estimate of combined exposure from pesticides, flavourings, feed as well as personal care products. In both cases, the exposure 
assessments were carried out using individual food consumption data from the EFSA's Comprehensive Database.

Some of EFSA's guidance documents also suggest providing information on known oral exposure from non-food sources (cosmetics, medicines, toys, etc.). However this information is only qualitatively included in scientific opinions, e.g. flavourings and food additives, and not taken into account in an overall exposure assessment from all source and all routes. Although this might be desirable from a scientific point of view, such assessments are very resource demanding and often are not necessary when it can be anticipated that exposure sources other than diet are not contributing much to the overall burden.

A summary of EFSA's approaches to exposure assessment is presented in Table 7.1.

\section{2 ЕСНА}

\subsubsection{Introduction}

Andreas Ahrens

The European Chemicals Agency (ECHA) in Helsinki was set up in 2007 in order to manage the implementation of the new European Chemicals legislation on Registration, Evaluation, Authorisation and restriction of $\mathrm{CHemicals}$ (REACH). As of January 2018 about 560 employees from 25 EU Member States are working at the Agency.

REACH has introduced a number of new paradigms for regulating chemicals. Implementation of the paradigms is expected to significantly increase the safety of products and processes regarding risk from chemicals. The emphasis is on generation, dissemination and use of knowledge under the responsibility of industry, based on a harmonised level playing field across Europe. Where generation of more knowledge and risk management under responsibility of industry cannot work or does not sufficiently work in practice, REACH foresees complementary mechanisms for regulatory risk management.

It is ECHA's task to technically support the new system and its core processes. This secretariat function also includes the power to make decisions together with the Member States. To help with better understanding of ECHA's role in connection to consumer exposure assessment under REACH, this chapter will reflect on the main regulatory innovations, explain the key REACH processes, and provide a short overview of the different committees working with ECHA. 


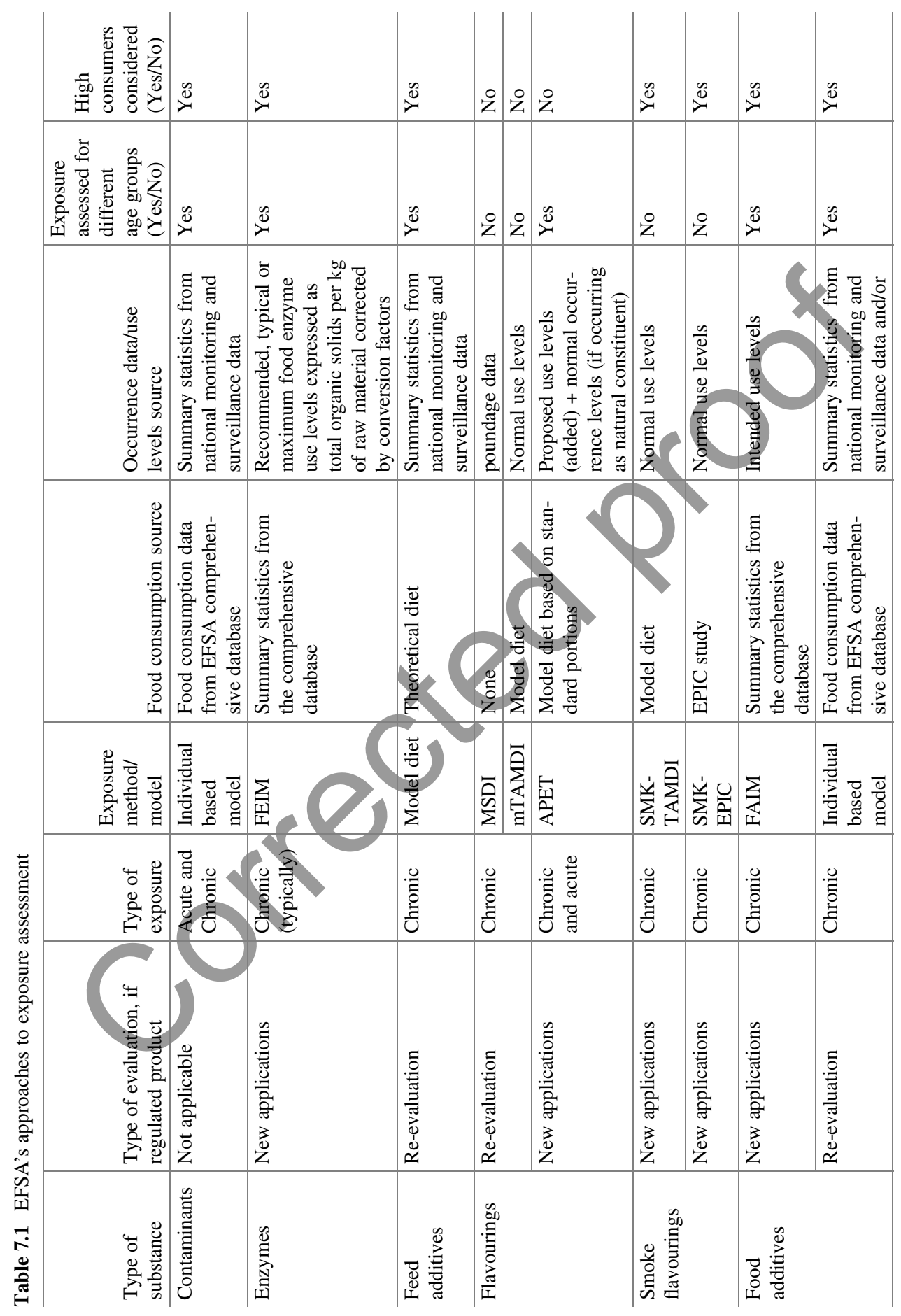




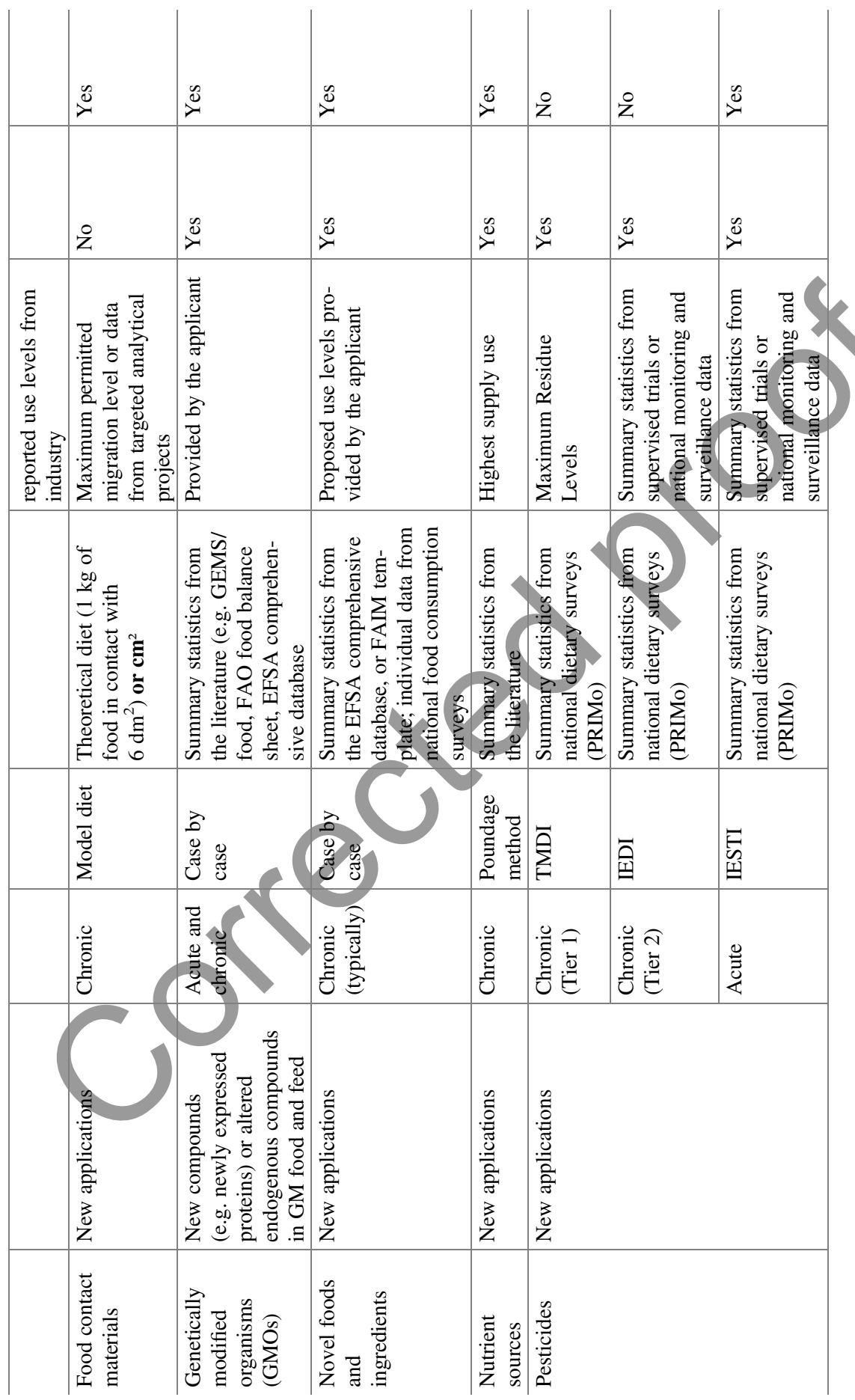




\subsubsection{What Is New?}

REACH introduced a number of new principles and paradigms in regulating chemicals:

- The new rules apply to all substances manufactured or imported in quantities of one tonne or more, independent of when they had been placed on the market for the first time.

- Manufacturers and importers are obliged to register their substances with an obligatory set of data to characterise the intrinsic properties and the related hazards.

- REACH requires cooperation among registrants. Each registrant has to characterise the identity of his substance (including its composition), and all registrants of the same substance shall exchange their information on the substance, and submit a joint data set. Testing is required when information is lacking. For vertebrate testing REACH foresees that authorities evaluate industries' testing proposals beforehand.

- Exposure and risk assessment are required when hazards are identified.

- The responsibility to identify the existing uses of a substance and to demonstrate how the substance can be used safely is placed on industry (as the registrant's Chemical Safety Assessment). The safety assessment shall cover the whole life cycle of the substance from manufacture, the formulation into mixtures, and the use of mixtures down to the use of the articles into which the substance has been incorporated. The assessment is to be carried out for each use. In addition, the registrant should assess the cumulative exposure from the different uses of a substance.

- Suppliers are obliged to include use-specific safety advice into their safety data sheets (exposure scenarios), and the recipients are obliged to respond, i.e. follow the advice or carry out their own safety assessment. The risk management advice may address technical measures and personal protection equipment for workers, measures to control environmental releases from industrial sites, and advice for the design of consumer products (e.g. concentration of substance and the size and form of the package).

- The non-confidential information from the registration dossiers, as submitted by the registrants, is automatically disseminated via ECHA's website, in order to provide public access to information about the intrinsic hazards of the substances placed on the EU market, and their use patterns.

To make the registration mechanisms and the subsequent communication in the supply chain work under the responsibility of industry, REACH foresees a number of processes run by the authorities such as checking the completeness and compliance of registration dossiers (by ECHA). 
As a second pillar of REACH, ECHA and Member States together set up a rolling action programme for evaluating substances (by Member States) that may require regulatory risk management at the community level (CoRAP). The selection of substances for CoRAP is risk-based, i.e. hazard and exposure concerns play a role.

The pre-existing regulatory risk management by harmonised classification and labelling and restrictions has been maintained under REACH.

One of the main novelties under REACH is a particular regime for substances of very high concern (SVHC). These are substances causing serious long-term effects, and in particular those where no safe level of exposure can be established, or where such level is very uncertain. Typical examples are genotoxic substances and substances toxic to reproduction and/or development, or substances persisting and bioaccumulating in the environment. In a first step, based on a recommendation by ECHA, substances with confirmed properties of very high concern are placed on the candidate list of substances for authorisation. In a second step, the substances from this list are selected for authorisation, which means that from a certain point in time (sunset date), only authorised uses are permitted, and this is only for a limited time span.

If such substances are contained in articles, such as textiles, electronic goods, toys, and furniture, special rules apply for notification to authorities and for communication to consumers. The rules are particularly relevant to substances in imported articles, as these are not covered by the REACH registration regime.

\subsubsection{REACH Processes, Consumer Exposure Assessment, ECHA's Role}

Implementation of these paradigms takes place through a number of REACH processes managed by ECHA and its Committees. The following section provides an overview on a few key processes.

\section{Registration}

For substances having production amounts greater than 10 tonnes per year, registrants submit a technical dossier and attach a Chemicals Safety Report (CSR) documenting the registrant's safety assessment. This includes classification and derivation of no-effect levels for the various toxicological endpoints, and determination of chemical-physical properties that drive the behaviour of the substance when used, when treated in waste water/air, or after release into the environment. Behaviour in the environment is of particular relevance for predicting indirect 
exposure of the population through the food chain. Where hazards have been identified, the CSR includes a description of the conditions of use, corresponding exposure estimates and a comparison with the derived no-effect levels. Registrants are requested to demonstrate how the substance should be used in products and processes, so that the expected exposure remains below the effect level. Based on this assessment, registrants communicate the conditions of safe use in the form of exposure scenarios to their customers, for example the producers of mixtures or articles for consumers.

ECHA provides guidance and tools to registrants to collect, assess, document and submit this information. The guidance and tools have been developed in consultation with industry and Member States. The key tools are REACH IT (system to run the registration business), IUCLID (tool for the technical dossier, i.e. the substance data set) and CHESAR (a tool to carry out and report the chemicals safety assessment based on the substance data set stored in IUCLID). In the 2016 update of IUCLID, much emphasis was put into increasing the transparency of the relationship between substance compositions/form, the tested material, and the outcome in terms of toxicological characterisation. Thus, the tools for data submission provided by ECHA impact the transparency and consistency of assessments.

ECHA checks the completeness of the incoming dossiers in an automated or semi-automated way. Incomplete dossiers are stopped and the registrant gets the opportunity to complete the dossier.

In order to avoid too many dossiers getting blocked and to support a minimum quality of the registration dossier in terms of consistency and plausibility, IUCLID is equipped with a validation assistant to help the registrant avoid obvious and unintended shortcomings of their dossier.

Registrants need to decide whether they want to support the use of their substance in mixtures and/or articles for consumers. If not, they do not include uses by consumers in the corresponding IUCLID section of their registration, and might explicitly advise against consumer uses in the safety data sheet. For supported consumer uses, the registrants must determine the safe concentration of the substance in the different consumer products and a safe amount per use event. They may also advise controlling exposure via package design, such as dissolvable packaging for portions of dishwashers detergents or very small amounts per package for hazardous adhesives.

\section{Dissemination}

Most of the information in the Technical Dossier is automatically disseminated via ECHA's website so that there is online access for the public and others to the information on (1) the properties of the substance, including classification, labelling, derived no-effect levels (for human health) and predicted no-effect levels (for the environment), and (2) its use pattern(s). Only information that is by default confidential (e.g. details on substance composition and on manufacturing and use 
processes), or that has explicitly been claimed confidential (including a justification) is not disseminated.

Also, the conditions of safe use, determined in the Chemical Safety Assessment, are accessible via ECHA's website, but only to the extent registrants have transferred this information voluntarily from their CSR into the IUCLID dossier. ECHA's safety assessment tool for registrants, CHESAR, is particularly equipped to transfer the results of the exposure assessment (the conditions of safe use, exposure estimates per activity, and corresponding risk characterisation) into the IUCLID dossier.

As a result of dissemination, it is for example possible to identify all substances that are reported to be used in mixtures or articles for consumers, and to identify the types of mixtures and articles in each case. The granularity and accuracy of the information differs a lot from registrant to registrant as there are no definitive legal requirements about how the uses of a substance are to be described.

The information disseminated via the ECHA website is not checked by authorities beforehand, and the current quality is quite diverse across the registrants. It is expected that registrants will improve the information depending on how much industry itself, NGOs, academia/ media, and the general public reviews and works with the information.

\section{Dossier Compliance Check}

ECHA is obliged to evaluate the compliance of the registration dossiers. This REACH process aims to ensure that the registrant community as a whole fulfils their duties, rather than checking correctness and accuracy of each single dossier and each single information requirement. In a compliance check, ECHA particularly concentrates on the substance identity (including the substance composition) and the information endpoints related to the identification of the presence or absence of major hazards. Examples include genetic toxicity, toxicity to reproduction or development, repeated dose toxicity, aquatic toxicity, bioaccumulation, and environmental degradability.

The checks on the substance identity profile are particularly important for ensuring that the composition of the registered substance is clearly defined (including its impurities), and that the available test data and the corresponding hazard characterisation match this composition.

Uses, conditions of use, and exposure play a particular role in compliance checks when the registrant has adapted information requirements based on exposure considerations (i.e. waives required tests), or when determining whether an additional dermal or inhalation study would be required.

\section{Substance Evaluation}

Based on the community rolling action program (CoRAP), Member States evaluate substances when there is a concern of controlled risks at a community level. For 
example, this could be the case where significantly hazardous substances are reported to be used in consumer products (information from REACH registration database or from other sources). As of October 21, 2019 the CoRAP list contains 375 substances.

\section{Classification and Labelling}

Member States may also propose a harmonised classification of a substance, based on the criteria laid down in the CLP regulation. This proposal is then examined by ECHA's Risk Assessment Committee (RAC). Any classification as a CMR has by default the consequence that the substance is banned for use in mixtures for consumers.

\section{Determine Candidates for Authorisation}

Based on the intrinsic properties of the registered substances, ECHA or Member States make proposals for identifying substances as being of very high concern (SVHC), for example because they are genotoxic carcinogens, mutagens, toxic to reproduction or development, or because they persist and accumulate in the food chains. The high concern relates to the seriousness of the effect and the low dose at which it occurs, or to the fact that a safe level cannot be determined. The proposals are subject to a public consultation. Substances fulfilling the criteria are then included in the candidate list for authorisation. By October 21, 2019 two hundred and one substances are listed as candidates.

As soon as a substance has entered into this candidate list, all (consumer) articles containing this substance need to be notified to ECHA (unless already registered for that use in the EU), and consumers may ask the companies they purchase the article from for advice on safe use. Producers or importers of articles being confronted with such duties usually try to find less hazardous alternatives for the substance.

\section{Inclusion of Substances into the Authorisation List}

Once a year, ECHA recommends a number of substances from the candidate list to be included into the list of substances for authorisations. Priority is given to substances in widely dispersed usage and/or placed on market in high volumes, and/or being PBTs/vPVBs. The proposal is again subject to public consultation. By October 21, 2019 forty-three substances have been placed on the authorisation list. Once a substance has been included in the authorisation list, companies that want to continue its use after a certain sunset date have to apply for an authorisation with ECHA. Based on a safety assessment, applicants will explain how exposure is minimised on use and which risk(s) remain. For many substances (those without 
safe level), the applicant also needs to demonstrate that no safer alternative exists at present.

\section{Restriction}

Restrictions are a tool to protect human health and the environment from unacceptable risks posed by chemicals. Restrictions may limit or ban the manufacture, placing on the market, or use(s) of a substance. A restriction applies to any substance on its own, in a mixture or in an article, including those that do not require registration. It can also apply to imports.

A Member State, or ECHA on request of the European Commission, can propose restrictions if they find that the risks need to be addressed on a European Union-wide basis. ECHA can also propose a restriction on articles containing substances that are on the Authorisation list (Annex XIV). Anyone can comment on a proposal to restrict a substance.

Restrictions play a particular role for consumer exposure via articles. Where articles are manufactured outside the community, restrictions may prevent certain articles entering the community when they contain certain hazardous substances and using the articles may cause adverse health or environmental effects.

\subsubsection{Committees}

The above processes rely on the work of a number of committees associated to ECHA.

\section{Committee for Risk Assessment}

The Committee for Risk Assessment (RAC) prepares the opinions of ECHA related to the risks of substances to human health and the environment in the following REACH and CLP processes. The final decisions are taken by the European Commission.

RAC examines the proposals for harmonised classification and labelling and gives an opinion on the proposed harmonised classification of substances as carcinogenic, mutagenic, toxic for reproduction, or as a respiratory sensitiser, as well as other effects on a case-by-case basis.

The Committee also evaluates whether a proposed restriction on manufacture, placing on the market, or use of a substance is appropriate in reducing the risk to human health and the environment. This includes the assessment of comments submitted by third parties.

Finally, the RAC assesses the risk of a substance arising from the uses of a substance when an application for authorisation is submitted. This includes an 
assessment of the appropriateness and effectiveness of the risk management measures as described in the authorisation application, and if relevant, the risks of possible alternatives. Third party contributions linked to the application will also be assessed.

\section{Member State Committee}

The Member State Committee (MSC) participates in several REACH processes such as evaluation and authorisation. The MSC is responsible for resolving divergences of opinions among Member States and on proposals for the identification of SVHCs. The Committee provides opinions on ECHA's draft recommendation for the authorisation list (Annex XIV) and the draft Community Rolling Action Plan (CoRAP) for the substance evaluation process. If an agreement is not reached within the MSC, the matter is referred to the European Commission for decision-making.

When amendments related to ECHA draft decisions on testing proposals or dossier compliance checks are proposed by Member States, the MSC seeks unanimous agreement.

The MSC also seeks unanimous agreement on Member State draft decisions on substance evaluation when amendments are proposed to them by other Member States or ECHA. The MSC takes into account the comments of the registrants on the proposed amendments to the draft decisions based on dossier and substance evaluations. Once agreed by the MSC, ECHA finalises the decision and provides it to the registrant.

The MSC has an essential role in seeking agreement on the identification of Substances of Very High Concern (SVHCs). It also provides opinions on ECHA's draft recommendations on priority substances for inclusion in the authorisation list (Annex XIV).

ECHA takes into account the MSC opinion when finalising its recommendation to the Commission on priority substances for inclusion in the authorisation list.

\section{Committee for Socio-economic Analysis}

The Committee for Socio-economic Analysis (SEAC) prepares the opinions of ECHA related to the socio-economic impact of possible legislative actions on chemicals in the following REACH processes. The final decisions are taken by the European Commission.

It evaluates the socio-economic impact of the proposed restriction on manufacture, placing on the market or use of a substance. This includes the assessment of comments and socio-economic analyses submitted by third parties.

SEAC also assesses the socio-economic factors and the availability, suitability and technical feasibility of the alternatives associated with the uses of a substance when an application for authorisation is submitted. Third party contributions linked to the application will also be assessed. 


\section{The Forum}

The Forum for Exchange of Information on Enforcement (Forum) is a network of the national authorities responsible for the enforcement of the REACH, CLP and PIC regulations.

The Forum sets its work programme based on the list of tasks specified in the REACH, CLP and PIC regulations. The practical work of the Forum is divided between ten working groups that provide solutions to specific areas of enforcement. The Forum holds three plenary meetings every year.

\subsection{Activities of the European Commission: Joint Research Centre \\ 7.3.1 The EIS-ChemRisks Toolbox ${ }^{16}$}

\section{Alexandre Zenié, Vittorio Reina, and Demosthenes Papameletiou}

In 2003, DG JUST requested the JRC to develop a European information system on chemical risks from consumer products and articles (EIS-ChemRisks). This project aimed to collect information and provide tools and reference data to enable the design of harmonised exposure assessment procedures for consumer products and articles throughout the EU. The EIS-ChemRisks project was carried until 2009.

The work carried out led to an EU exposure assessment toolbox prototype, called EIS-ChemRisks that supports stakeholders (e.g. authorities, industries, research organisations, academia and NGOs) in the EU to carry out assessment of consumer

\footnotetext{
${ }^{16}$ Acknowledgement: Without the participation and the dedication of the following team members the EIS-ChemRisks toolbox would not have been possible: Pertti (Bert) Hakkinen, Dieter Schwela, Yuri Bruinen de Bruin, Carlos del Pozo, Irene Biavetti, Athanasios Arvanitis, Giorgios Giannopoulos, Majlinda Lahaniatis, Stylianos Kephalopoulos and Dimitris Kotzias. Particular thanks are expressed to Takis Daskaleros (DG SANCO).

Many thanks to the JRC colleagues from the European Chemicals Bureau (ECB), namely: BertOve Lund, Jens Tørsløv and Frans M. Christensen.

Special thanks for the continuously involved experts, namely: Jacqueline van Engelen (RIVM), Gerhard Heinemeyer (BfR), Anne Catherine Viso (InVS), Lea Frimann Hansen (DEPA), Leif Bengtsson (KEMI), Matti Jantunen (KTL) and Carlos Rodriguez (P\&G).

The following members of the IRAG sub-group have dedicated efforts on case studies carried out using the EIS-ChemRisks toolbox: Dirk van Aken [Food and Consumer Product Safety Authority, the Netherlands], Peter Hammer Sørensen [Environmental Protection Agency (DEPA), Denmark], Matthias Honnacker [Federal Institute for Occupational Safety and Health (BAuA), Germany], Janez Novak [Market Inspectorate, Slovenia], Corinne Mandin [Institut National de l'Environnement Industriel et des Risques (INERIS), France], Konstantinos Zisis [Ministry of Development, Greece] and Chris Van der Cruyssen [Federal Public Service Economy, Belgium] with the coordination of Jürgen Vogelgesang (DG SANCO). We are grateful to all of them.
} 
exposure from the use of consumer products in a harmonised way. The EIS-ChemRisks toolbox prototype was used and tested by selected experts.

\section{Concept}

The main concept behind the European exposure assessment toolbox relies on scenario-based consumer exposure assessment over several rounds of stakeholders' dialogue. This aims to continuously improve existing consumer exposure scenarios as soon as new determinants, new algorithms or methods become available (Heinemeyer et al. 2006; van Engelen et al. 2007).

The adopted consumers' exposure assessment is conducted into six consecutive steps before storing the resulted scenario within the ExpoScenarios library:

1. Defining the general information including the source document, the disclaimer and the issue at stake

2. Setting the problem definition including the source, the chemical, the target population, the exposure event, the considered microenvironment, the risk management measures, the chemical release, the exposure pathways, the exposure routes and the building procedure on the basis of the guidance documents

3. Selecting the adequate mathematical algorithms evaluating the exposures in harmony with the concept

4. Selecting the reference data adequately by using chemical-specific determinants and exposure factors to be used within the selected algorithms

5. Evaluating the exposure results on the basis of previous steps

6. Highlighting commonalities with other exposure scenarios from the library in order to interpret the results.

\section{Architecture}

At the contrary of the linkages compendium approach adopted later on by the US-EPA's exposure assessment toolbox (EPA-Expo-Box) (Phillips et al. 2015), the EIS-ChemRisks toolbox integrated several databases and tools within the following six modules to act as a reference harmonised documenting system:

- ExpoData collecting data and information on chemical-specific exposure data (e.g. substance content in specific products and articles, related emission or migration data and related substance concentrations in environmental media or body parts or fluids)

- EU-ExpoFactors collecting data and information on exposure factor [e.g. anthropometric data (human body weight, breathing rates for various types of consumers), time use data and product use frequencies]

- Chem-Test inventorying exposure testing methods (e.g. measurement methods to quantify emission of chemicals from consumer products and articles)

- ExpoModels inventorying exposure models, relative algorithms (e.g. algorithms for assessing dermal exposure to chemicals in products used for a specific purpose such as cleaning) and adequate concepts 
- ExpoScenarios collecting libraries of available consumers' exposures assessments compiled from EU and international risk assessment resources integrated by a scenario generator facility aiming to develop new exposure assessments using a standardised procedure and presentation template

- ExpoHealthData, cataloguing human health data associated to specific consumer exposure scenarios (e.g. physician reports in publications of human skin irritation and sensitisation associated with particular chemicals used in consumer products and articles).

Figure 7.1 displays the EIS-ChemRisks toolbox workflow, based on the concept of integration of several databases and tools in six modules.

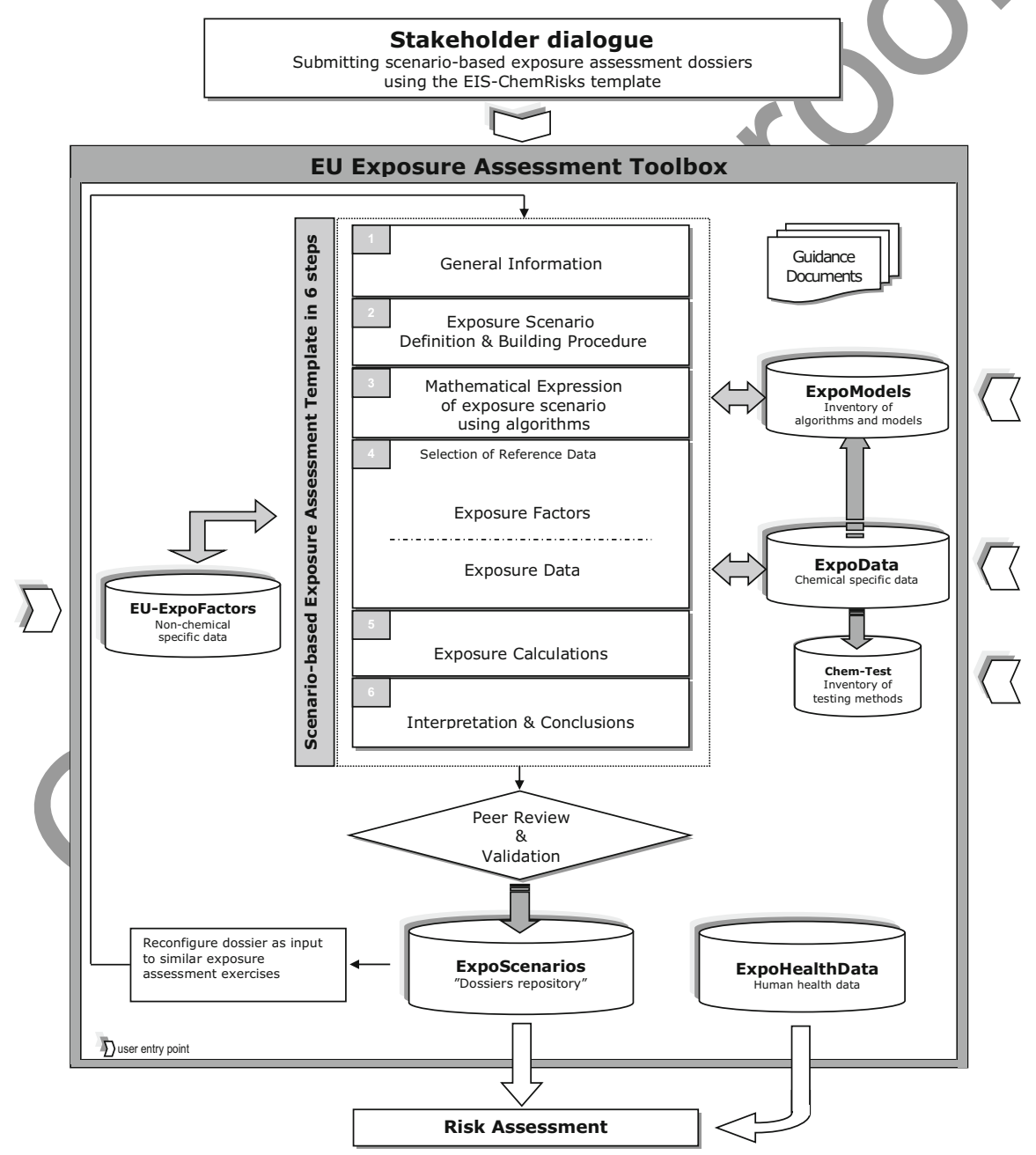

Fig. 7.1 The EIS-ChemRisks toolbox concept workflow 
The toolbox approach was specifically designed with an open architecture which is modular and easily adaptable to specific needs arising from the implementation of particular management policies.

\section{Implementation}

The EIS-ChemRisks project maintained a home page in order to continuously collect user feedback as well as to disseminate general information and specific user guidance documents. Furthermore, the EU Exposure Assessment Network ensured that the needs of different stakeholders and of different policy areas were adequately catered for within the toolbox.

The toolbox represented a unique reference system for consumer exposure scenarios that were applied in exposure and risk assessments in the EU and globally. It was publicly accessible from the site http://www.jrc.ec.europa.eu/eis-chemrisks and several access levels were allowed in order to maintain the sensitivity of the information.

The toolbox allowed users to access information and make queries from 5771 primary source documents and 477 harmonised consumer exposure scenarios, in order to find exposure scenarios details, exposure determinants including exposure factors, testing methods and exposure models including algorithms (van Leeuwen and Vermeire 2007).

The EIS-ChemRisks toolbox enhanced the mapping of chemicals occurring in consumer products with a view to listing all chemicals which are reported in each consumer product, according to the available taxonomy. The mapping can be confined to a specific information source, e.g. RAPEX notification or risk assessment report.

The exposure scenarios library can also be filtered by chemical, consumer product and/or risk management measure (RMM) for consumer products defined within the exposure scenarios (Bruinen de Bruin et al. 2007). Furthermore, this library can be restrained to a geographic entity such as region, country, EU, worldwide, specific microenvironment such as indoor and a specific target population such as neonate, preterm neonate, full-term neonate, infant, toddler, child, adult, adolescent and elderly.

A standardized format for storing exposure scenarios, as implemented in the EIS-ChemRisks toolbox, allows the use of the EIS-ChemRisks toolbox as a documentation system serving as a library of the different types of consumer exposure scenarios. An example is given in Appendix 2.

In addition to enabling scenario-based exposure assessment in a standardized way, the EIS-ChemRisks project offered multidisciplinary training opportunities for exposure assessors within the EU. Training modules were developed, tested and applied by several experts.

Finally, the EIS-ChemRisks concept, as applied in the toolbox for consumer exposure to chemicals, provided a model for carrying out assessments related to physical hazards. Such formalisation of a consumer exposure assessment process 
was implemented in the Commission Decision 2010/15/EU of 16 December 2009, laying down guidelines for the management of the RAPEX notifications system of the GPSD directive (EU 2002, 2010).

\subsubsection{EXPO-Facts}

Alexandre Zenié, Vittorio Reina, and Artur Radomyski

\section{Introduction}

The EXPO-Facts project was originally funded by the Long-Range Research Initiative (LRI) of the European Chemical Industry Council (CEFIC) (contract no. NMALRI-C1.5KTL-0207 and LRI-C1.5.1-KTLE-0512) and contracted to the Finish National Public Health Institute (KTL, Finland). It complemented the ECETOC sourcebook that focused on the UK (Zaleski and Gephart 2001). The project was undertaken in the period from 2002 to 2006 (Vuori et al. 2006). Given its EU-wide perspective, the EXPO-Facts database was then handed over to the European Commission's Joint Research Centre (JRC), and became available online on 15 January 2007 via the EU Science Hub.

Non-chemical exposure factors are considered as the actions, the media and the microenvironments that bring humans in contacts with agents (e.g. housing conditions, time use in different microenvironment and product use). They complement the chemical specific exposure data and serve as input for exposure models in order to quantify the human exposure to chemicals (Zaleski et al. 2016).

The EXPO-Facts database contains non-chemical exposure factors, data and information which are relevant to exposure and risk assessment of chemicals, performed in the context of several sectorial EU regulations on environment and public health (e.g. REACH, BPR, GPSD, PPPR, CPR, food safety and nutrition and food contact materials). It also contains data and information on population data covering all EU Member States plus Iceland, Norway and Switzerland (31 countries in total) with extensive links and references. As a common gateway, EXPO-Facts serves to gather and disseminate European-based reference exposure factors data and information that were previously scattered in various sources (e.g. databases, information systems of national institutes and international organisations such as WHO and UNECE, scientific articles in peer-reviewed journals, reports and surveys from national studies). The EU EXPO-Facts related data and information have been compiled into an online database from over 120 sources.

The EXPO-Facts database is mainly a tool for European exposure assessors and risk managers involved in public health and environmental health issues, particularly in the areas of indoor air quality, dietary exposures and safety of consumer products 


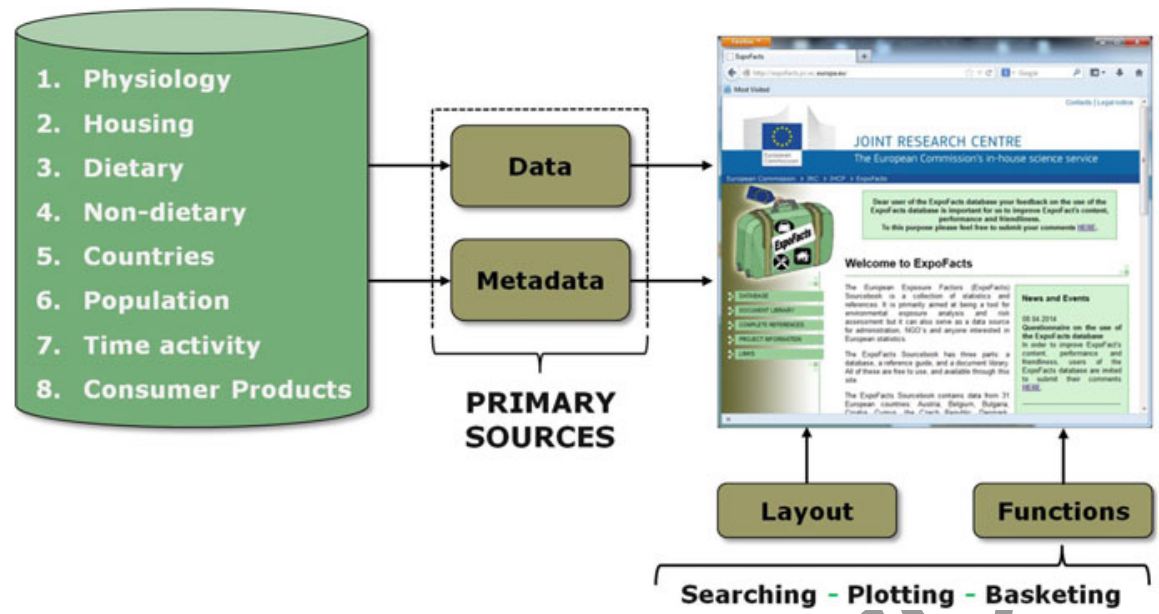

Fig. 7.2 Main components of the EXPO-Facts database

and articles. Data are mostly on diet, time-activity patterns, physiology, housing and demographic factors including non-dietary and consumer products (Fig. 7.2).

\section{Components of the System}

The database is built in straightforward manner. It offers several functionalities including categorising, querying, sorting, retrieving and visualising. Searching can be structural or through free text option that may be useful for survey-based data (Fig. 7.3). New functions are being developed to allow for the aggregation of data.

The EU EXPO-Facts is a web-based database that is freely accessible at: https:// ec.europa.eu/jrc/en/expofacts.

\section{Issues in Interpreting European Exposure Determinants' Values of the EXPO-Facts Database}

Data in EXPO-Facts are not processed but presented as originally found in the sources, for that reason the use of statistical measures is very heterogeneous and source-dependent.

EXPO-Facts has the peculiarity to present data of many countries with some tables being country-specific (e.g. Ventilation rates measured in homes in the Netherlands and Food consumption in Germany, Fig. 7.4). It should be noted that the data from various sources were collected using different survey methodologies and may represent different degrees of representativeness (Table 7.2). 


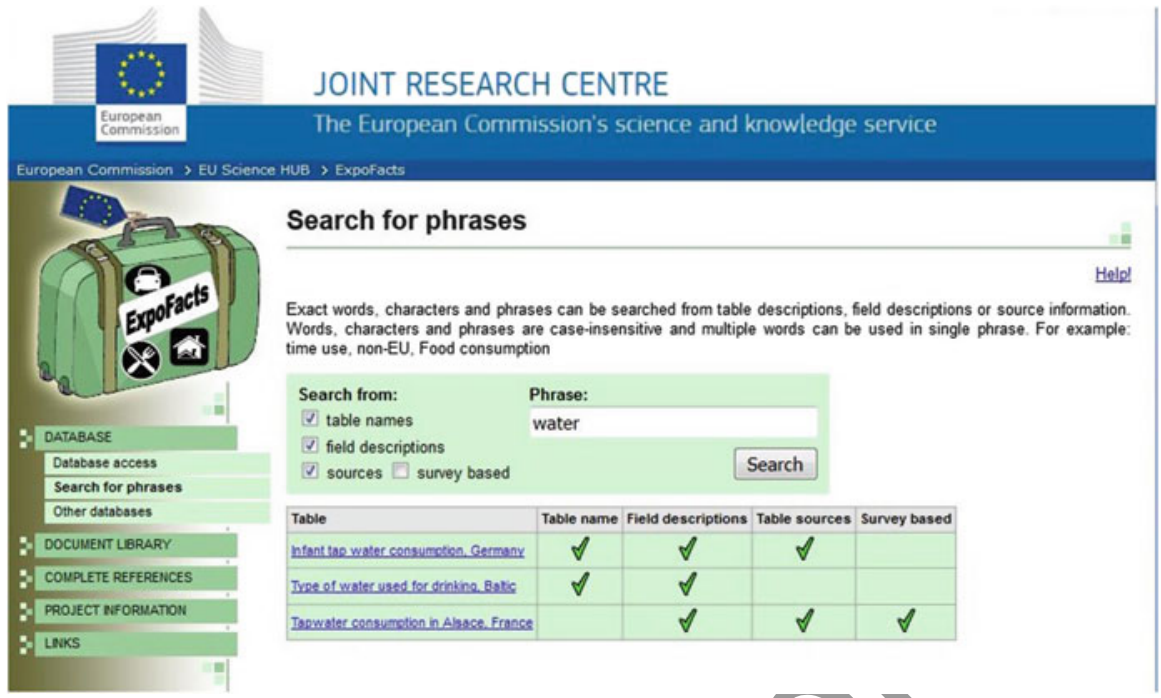

Fig. 7.3 Searching within the EXPO-Facts database

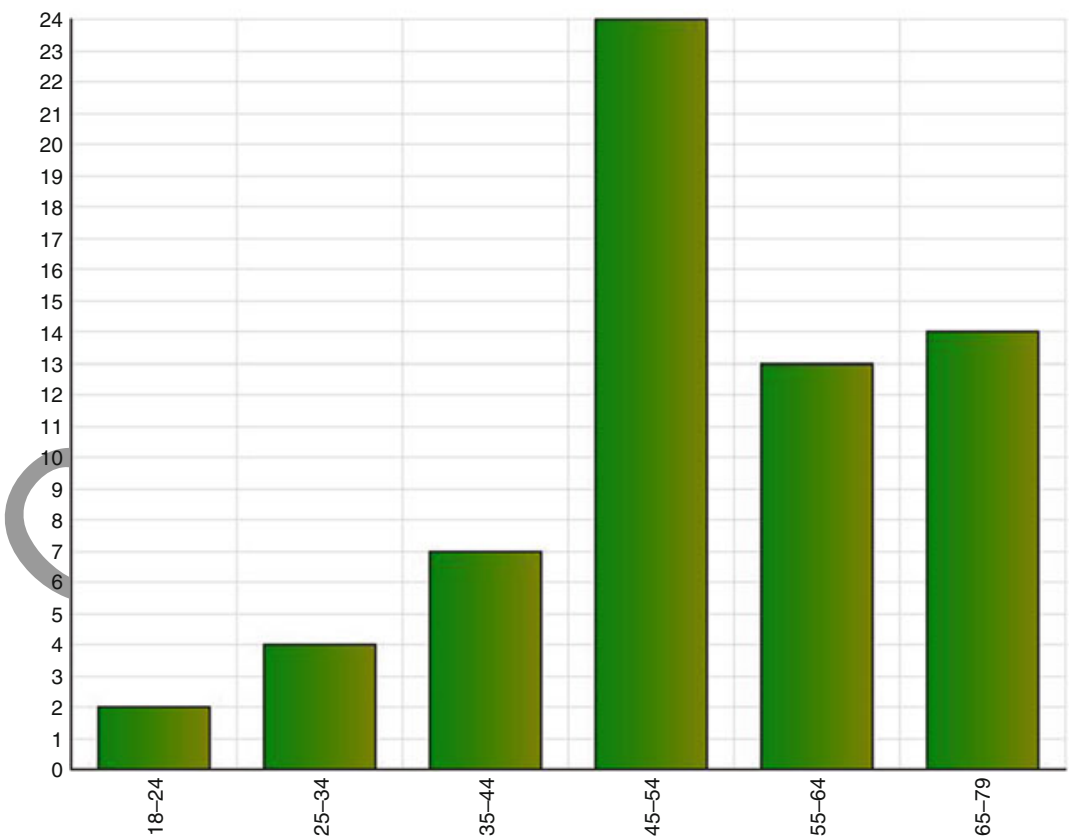

Fig. 7.4 Food consumption for different categories of age in Germany 


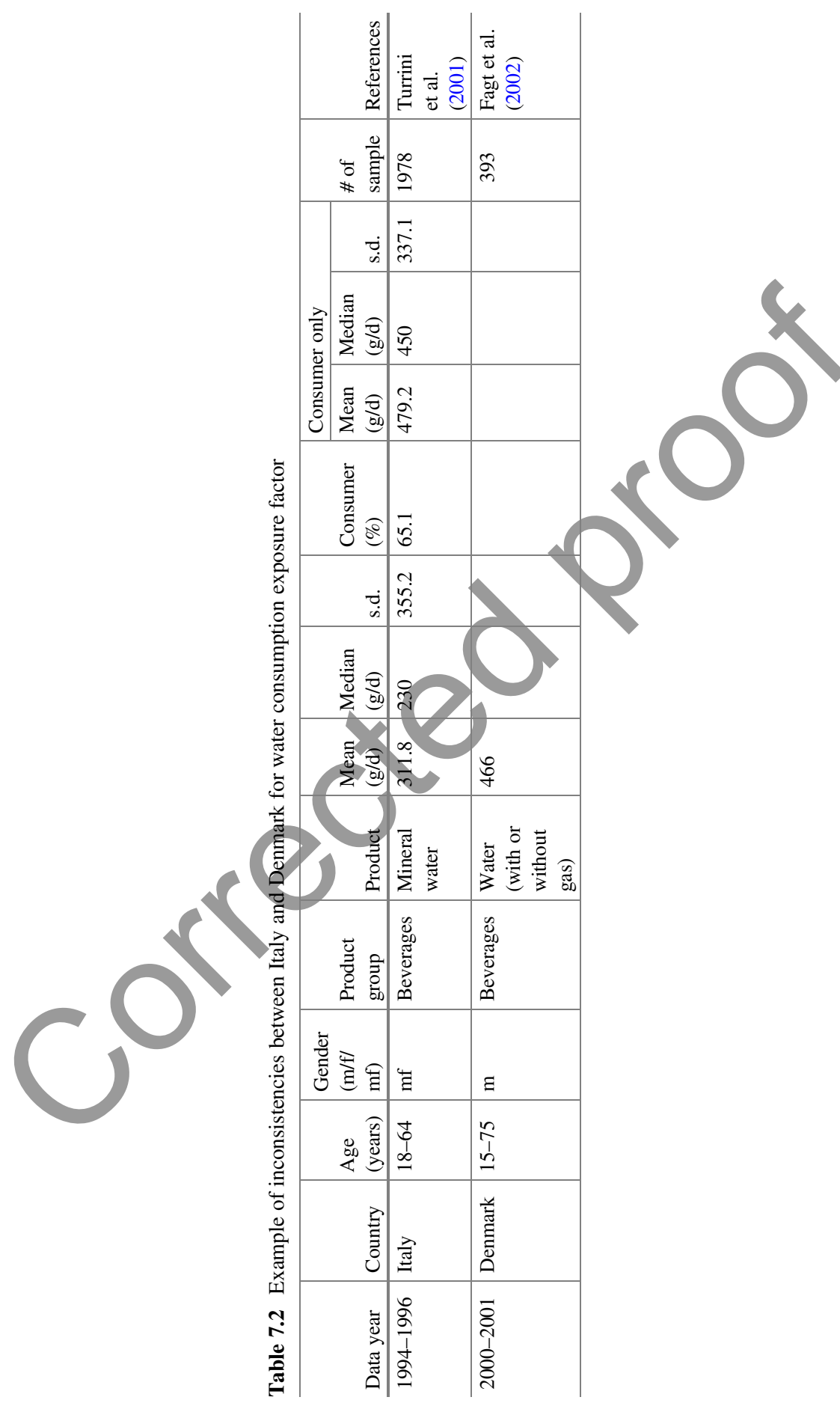




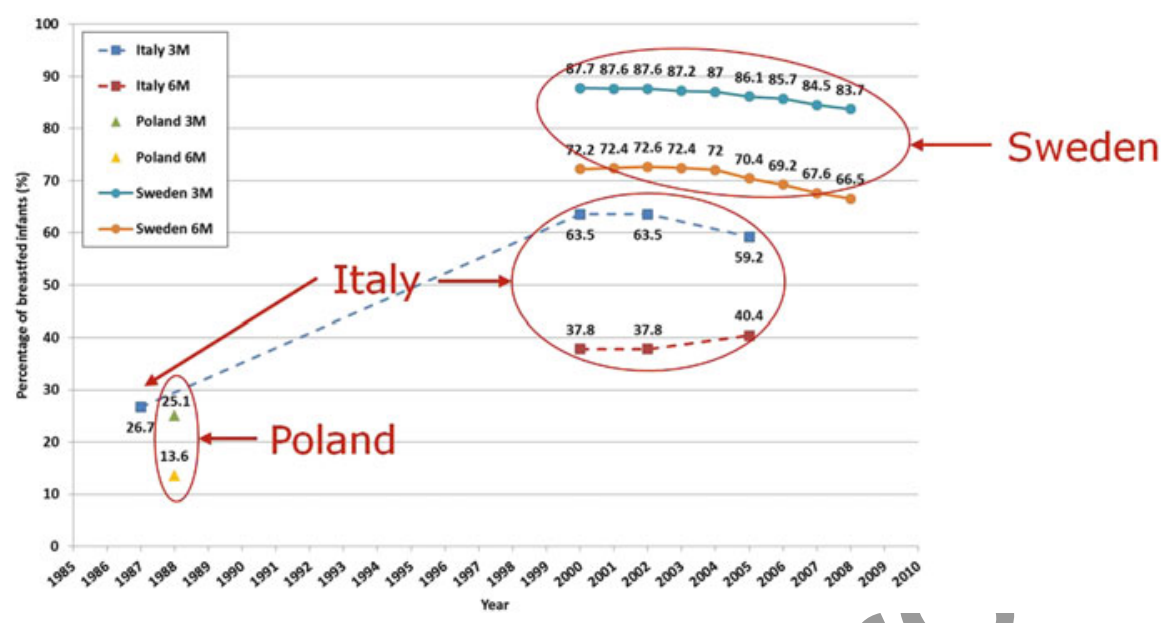

Fig. 7.5 Infants breastfed (\%) at the age of 3 and 6 months in Italy, Poland and Sweden

Consequently, in some cases, direct comparisons by age group or population groups between different countries can be inconsistent because of the ways in which they provide details and how the information is harmonised (Fig. 7.5):

- Selecting data over the lifetime of a population within a specific country can be misleading if several different primary sources were used for this coverage.

- Comparing across EU Member States for a specific exposure factor is not meaningful if several different primary sources were used in this analysis.

- Averaging over time for analysing the trend of a specific exposure factor can also be misleading if several different primary sources were involved.

\section{Recommendations for Systematic Approach to the Interpretation of the EXPO-Facts Exposure Determinants' Values}

The following three recommendations should be systematically considered for a meaningful interpretation of the EXPO-Facts exposure determinants' values.

- Checking the primary sources in order to get full insight of the source values

- Analysing the interval dimension of the data and the sample size before averaging the data

- Adopting advanced techniques such as interval analysis for using exposure determinants' values.

The interval dimension of the data can be computationally preserved by using interval analysis in low or intermediate tiers of exposure assessment. 


\section{Conclusions}

Although specific to the European population, the EXPO-Facts database includes explicit links to international exposure factors systems (i.e. Australia, Canada, China, Germany, Japan, Korea and the USA), with the aim of seeking harmonisation, interoperability and integration.

The interoperability between these exposure factors systems, where EXPO-Facts is playing a leading role due to its straightforward availability on the Internet, promotes on the one hand the development of standardised protocols for collecting data and on the other hand the correct interpretation and use of the exposure determinant values in harmonised manner.

A future development of the EXPO-Facts database could consider the inclusion of other factors, ranging from external dose to internal dose and target tissues, including biomarkers and factors needed for pharmacokinetic modelling to allow for dose reconstruction from human biomonitoring data.

\subsection{Activities by the WHO}

Gerhard Heinemeyer and Matti Jantunen

\subsubsection{Exposure Assessment Harmonisation in the Frame of the International Programme on Chemical Safety}

Based on the IFCS Bahia Declaration and the World Summit on Sustainable Development that called for common approaches to chemical risk assessment, the WHO initiated the international programme on chemical safety (IPCS). The aim of this project is to harmonize assessment approaches of risk from exposure to chemicals. Within this programme, the documents produced are generally in the form of guidance to be adopted for use by regulatory schemes. The work is not specific to a particular category of chemicals, but is applicable to the assessment of industrial chemicals, pesticides, food additives and contaminants, industrial by-products, etc., in general.

The project is directed to:

- The general public to enhance confidence and trust in assessment and regulation. An increased access to information would allow greater participation in risk management decisions. 
- Governments for increased access to risk assessment in global setting, cost savings through burden sharing, better risk assessment promoting safer chemical use.

- Industry in order to reduce testing costs, increase common data sets and consistency in interpretation of data, and improve risk characterisation leading to safe chemical use, and the

- Scientific community to promote sound science as the basis for decisions, and advances in innovative methodologies driven by identification of critical needs for data and new research.

An Exposure Assessment Planning Working Group was initiated to make proposals for emerging issues regarding exposure assessment. At the first meeting (1999 in Athens, Greece), four primary issues to advance harmonisation in exposure assessment were identified.

Working groups were formed to work out the following guidance documents:

1. Harmonisation of Chemical Exposure Assessment Terminology: The chairs of this project were Michael Callahan and Karen Hammerstrom (US-EPA).

2. Principles of Characterizing and Applying Exposure Models with Matti Jantunen as chair (Institute for Health and Consumer Protection at the Joint Research Centre, European Commission, Italy).

3. Uncertainty Analysis in Exposure Assessment chaired by Gerhard Heinemeyer (Federal Institute for Risk Assessment, Germany).

4. Data Quality Assurance in Exposure Assessment, which was performed in parallel with the uncertainty project as recommended by the Steering Committee, chaired by William C. Griffith (Institute for Risk Analysis and Risk Communication, University of Washington, Seattle, USA).

Project No. 1: Harmonisation of Exposure Assessment Terminology: (WHO 2004)

The Scope of this project was to develop a consistent framework and definitions for terminology in the field of chemical exposure assessment, with an objective to improve communication by harmonising definitions.

The group took exposure assessment-related terms from a collection of 57 glossaries for exposure and related fields, and developed a logically consistent framework of definitions for 39 key terms. Toxicological terms, risk-related terms, chemical names, procedural terms, and risk management terms were generally excluded. The Glossary was adopted by the International Society of Exposure Analysis (now the International Society of Exposure Science) in September 2004.

\section{Project No. 2: Harmonisation of Exposure Modelling (WHO 2005)}

First, the working group developed a concept for a conceptual or mathematical representation of the exposure process by means of the IPCS definitions. 
Models are mathematical representations of a natural system intended to mimic the behaviour of the real system, allowing for description of empirical data and predictions about untested states of the system.

Models can be characterised and applied based on the following principles:

- Terminology and definition

- 'Models' as tools for exposure assessment

- Mathematical/numerical representations of exposure scenarios

- Hierarchical aggregations of lower level (e.g. emission) models into a higher level (e.g. exposure) model.

A set of characteristics of a model that should be provided by the model developer and considered by the model user to be considered was developed:

1. Description of the purpose of the model and its components

2. Individual- or population-level analysis (level of aggregation)

3. Modelled time resolution

4. Applicability to diverse exposure scenarios

5. Description of data inputs

6. Model processes

7. Model code and platform

8. Model performance and evaluation summaries

9. Description of model outputs

10. Model sensitivity and uncertainty.

The guidance document 'Principles of characterising and applying exposure models' was issued by WHO in 2005.

\section{Project No. 3: Uncertainties in Exposure Assessment (WHO 2008, Part I)}

With this project and the corresponding preparation of a guidance document, the IPCS started to consider uncertainty as a central issue in exposure assessment. Uncertainty represents the laek of knowledge about factors affecting exposure or risk and can lead to inaccurate or biased estimates of exposure. Uncertainty must be separated from variability. The document is targeted for practical-level exposure assessors with limited experience in uncertainty analysis.

Focusing on the following issues, the guidance document in the form of a monograph gives a broad overview on uncertainty analysis:

- Scenario uncertainty

- Parameter uncertainty

- Model (construct) uncertainty

- Principal methods of uncertainty analysis

- Discuss harmonisation aspects

- Tiered approach for exposure assessment.

Several guidance documents that deal with uncertainty analysis reference the IPCS document, as seen in Sect. 3.8. 


\section{Project No. 4: Data Quality and Exposure Assessment (WHO 2008, Part II)}

This document addresses:

- Collection and use of exposure data

- Reasons for quality consideration needs

- Description of the principles of data quality

- Brief illustrative examples that highlight the importance of the key principles.

Quality assessment and uncertainty analysis are addressed together in one guidance document. A particular section of this book is also relevant (Sect. 3.7).

As stated in the introduction of this book, two of the editors participated in the work of the exposure harmonisation group. The consideration of the principles laid down in the IPCS guidance documents are therefore of the greatest concern. As pointed out in several chapters, the objectives of harmonisation have not yet been reached and a lot of commitment and work is still needed.

In addition, the IPCS activity on 'Risk Assessment of Combined Exposures to Multiple Chemicals' should be mentioned. This project developed a concept for a framework of risks assessment approaches for combined exposures. The project addressed a tiered approach starting with a broad scenario of combinations of various substances up be tiered for a defined scenario of well-known combinations of substances. The results of the project were presented at an international workshop organised by ILSI/HESI and hosted by OECD in 2011 in Paris, France (WHO OECD ILSI/HESI 2011), as well as a comprehensive report (Meek et al. 2011) (see also Sect. 7.6.4).

\subsection{Activities by OECD}

Yasmin Sommer

The functions of the Organisation for Economic Co-operation and Development (OECD) have shifted over the years of its existence. Today it is a globe-spanning intergovernmental organisation which provides the setting to discuss issues affecting the economic and social well-being including chemical safety. Here governments can exchange expertise, coordinate and harmonise policies, and set standards.

OECD's work is mostly carried out in specialised committees and their subsidiary bodies. They are composed of delegates from different countries, the European Commission, Industry/Trade Associations, and Non-Governmental Organisations (NGOs), and served by the OECD Secretariat, which is located in the Headquarters in Paris, France. More information about the mission and the way OECD works is available from the OECD website (http://www.oecd.org/about/).

The 'Chemicals Management Programme' is one part of OECD's chemical activities. It includes nanomaterials, pesticides, and biocides, and is overseen by the Chemical Committee. Consumer Exposure Assessment is addressed by several of the subsidiary bodies contributing to this work programme, e.g. the Working 
Party on Nanomaterials and the Working Party on Exposure Assessment (formerly known as Task Force on Exposure Assessment).

The Working Party on Nanomaterials was established in 2006. It develops methods and strategies for the identification and management of the potential risk of nanomaterials to the environment and human health. Among its activities is a project compiling the available tools and models used for assessing consumer exposure to manufactured nanomaterials. This project also aims to evaluate their applicability in exposure assessments characterising their performance. The Working Party on Exposure Assessment's scope was extended to include human health in 2008. Its mandate is to facilitate sharing, develop, disseminate, compare and, if possible, harmonise exposure-related information and exposure mitigation-related information, and methodologies and tools for assessment of the impact of the release of chemicals during their life cycle on the environment and on various human populations. In current practice 'exposure-related information' are the OECD Emission Scenario Documents (further explained below) and a work item on Internationally Harmonized Use Codes (Sect. 5.1.2). The term 'methodology and tools' comprises databases, guidance documents, harmonized templates, and exposure models.

Some examples of work items with relevance to consumer exposure are given below in the sections highlighting OECD work types. The Working Party on Exposure Assessment has currently taken up work items on Children's Exposure to chemicals and releases of chemicals from products. In cooperation with the Working Party on Hazard Assessment, it has also taken up work on combined exposures to multiple chemicals. Further information on the outcome of these efforts will become available over the next years via the respective sections of OECD's website on chemical safety. As a member of the United Nations Inter-Organisation Programme for the Sound Management of Chemicals (IOMC), OECD makes findings and workshop reports within the 'Chemicals Management Programme' publicly available. They are published free of charge on the OECD website.

The OECD website can be consulted for further information on the programme (http://www.oecd.org/chemicalsafety/). The publications on exposure issues are accessible from dedicated website subsections on the exposure assessment programme (http://www.oecd.org/env/ehs/risk-assessment/exposureassessment. htm) or website subsections on the OECD Series on Testing and Assessment (http://www.oecd.org/env/ehs/testing/

seriesontestingandassessmentadoptedguidanceandreviewdocuments.htm).

Information regarding OECD activities and findings on the safety of manufactured nanomaterials can be obtained via a different section of the OECD website (http://www.oecd.org/science/nanosafety/) and a subsequent link to the publications within the OECD series on the Safety of Manufactured Nanomaterials (http://www.oecd.org/env/ehs/nanosafety/publications-series-safety-manufacturednanomaterials.htm). 


\subsubsection{OECD Emission Scenario Document (ESD)}

The documents in the OECD Emission Scenario Document (ESD) series cover release estimations of chemicals during their life cycle including production, processing, use, service-life, recycling, treatment, and disposal phase. Primarily developed for environmental exposure assessment benefits, they also provide data for consumer exposure assessments, e.g. when information on typical product compositions is given as in the ESD No. 3 on plastic additives (OECD 2009). A list of all ESDs and access to them is available (http://www.oecd.org/env/ehs/riskassessment/emissionscenariodocuments.htm).

\subsubsection{OECD Harmonised Templates (OHTs)}

The OECD Harmonised Templates (OHTs) are standard data formats. They prescribe which information can be entered into and maintained in a database (e.g. IUCLID). Their principal users are developers of database systems. The benefit of the OHTs for assessors and regulators is that they facilitate a standardised electronic exchange of information between different stakeholders and databases. Most OHTs cover test study summary information on the properties or effects on human health and the environment of a chemical. The first set of OHTs concerning information relevant for exposure assessment became available in 2016. It covers 'use and exposure information' (OECD 2016). However, further work is required to address additional types of data in exposure assessment. All available OHTs are listed on the OECD website and accessible via it (https://www.oecd.org/ehs/tem plates/).

\subsubsection{OECD Guidance Documents}

OECD Guidance Documents provide counsel for performing the specified tasks and help to standardise procedures. One example is the 'OECD Guidance Document on Reporting Summary Information on Environmental, Occupational and Consumer Exposure' (OECD 2003). It contains three formats for the reporting of summary exposure information that allow sufficient flexibility to be used in various chemical assessment programmes. The formats enable accommodation of both quantitative (e.g. release rate and resulting exposure) and qualitative information (e.g. descriptions of the source of release and control measures). The user needs to determine the purpose, scope, and level of detail of the summary and complete the formats accordingly. Possible entries in the fields are explained in the guidance. Format A covers General Information and Overview of Exposure. This always needs to be completed and contains basic information about the chemical/category and an 
overall perspective on potential exposures. Available monitoring or modeling data can be summarised in the other two formats, Format B: Monitoring Evaluations and/or Format C: Modeling Evaluations.

More recently, the 'OECD Guidance Document for Exposure Assessment Based on Environmental Monitoring' (OECD 2013a) was published. It addresses both environmental and human exposure, and describes the basic methodology used to conduct an exposure assessment based on environmental monitoring data. The document focuses on common approaches despite the existence of fundamental differences between human and environmental exposure assessment methodologies. It aims to summarise the main facts and issues to be considered, e.g. the ways of using monitoring data in exposure assessments for differing purposes, data collection, sensitivity, and the quality of monitoring activities. It also includes a list of monitoring programmes in some OECD members states.

\subsubsection{OECD Surveys and Workshops}

Surveys are conducted to collect information and sometimes ratings on a specified subject from the participants. Subsequently, responses are compiled and also regularly evaluated. The outcome of a survey is always a source of information, e.g. 'Descriptions of Existing Models and Tools Used for Exposure Assessment' (OECD 2013b). In addition, survey results can serve OECD as a starting point to determine recommendations for further activities such as workshops or projects.

OECD workshops can be organised in cooperation with other organisations. One example relevant for consumer exposure is the 2011 'WHO OECD ILSI/HESI International Workshop on Risk Assessment of Combined Exposures to Multiple Chemicals' (OECD 2011a, b, c, d). It was organised by WHO and OECD, with input from the International Life Sciences Institute (ILSI). The workshop's purpose was to inform participants about the corresponding WHO framework and explore the application of the framework by discussing a number of case studies. In addition, information about current issues in combined exposure assessment was shared and the need for further work to be undertaken was identified. Meanwhile a formal programme to work on combined exposures to multiple chemicals was launched. In collaboration of the Working Party on Hazard Assessment and Working Party on Exposure Assessment, a first result, which includes considerations for the exposure characterisation informing assessments of combined exposures, was published in 2018 (OECD 2018).

Information on the results of surveys and workshops can be obtained on the OECD website (http://www.oecd.org/chemicalsafety/testing/seriesontestingandass essmentworkshopreportsmeetingreports.htm). 


\subsection{Anchoring Exposure Science in Europe}

Yuri Bruinen de Bruin, Jos Bessems, Peter Fantke, Natalie von Goetz, Urs Schlüter, and Alison Connolly

\subsubsection{Introduction}

Exposure assessment of stressors, e.g. chemicals, viruses, microbes, noise, and radiation, aims to understand the extent to which humans, organisms or non-living items in the environment are exposed. It contributes to exposure science in understanding situations that pose a potential risk to human health and the environment. Equally important to exposure assessment is to understand the hazards of such stressors that may lead to unwanted health and environmental effects. Both, exposure and hazard assessment sciences, are indispensable parts of risk assessment and subsequent analyses such as impact assessment and socio-economic analysis (Vermeire et al. 2017).

Many disciplines (NRC, 2012) need or at least benefit from knowledge in the exposure science domain (Fig. 7.5a, b). Exposure assessment is implemented in many EU regulatory legislative domains in the area of chemicals. As such, it is an important issue for many stakeholders such as (chemical) industry, national research institutes, NGOs, health insurance companies, (consultancy) companies in the occupational and public health arena, academia, research institutes, national and international policy makers, national and international agencies and authorities (Fig. 7.6).

\subsubsection{The International Society of Exposure Science (ISES): Corporate}

The role of many of these stakeholders is in one or more ways, and to a larger or smaller levels of detail, to pay attention to exposure as part of predicting, preventing or limiting risks, and to consider it as an essential element in the management or mitigation of the risks of chemicals and other stressors. Demands on the exposure assessment in the context of the various stressor-related disciplines are very diverse and to a large extent determined by the various exposed populations such as consumers, workers and ecosystems. In order to exchange knowledge and information globally, to discuss, learn and network the International Society of Exposure Analysis (ISEA) [subsequently renamed the International Society of Exposure Science (ISES)] was set up in 1989. The Society's mission is to meet the humanity's needs for public health and environmental protection through a global community of exposure science professionals. ISES encourages the open exchange of information, 

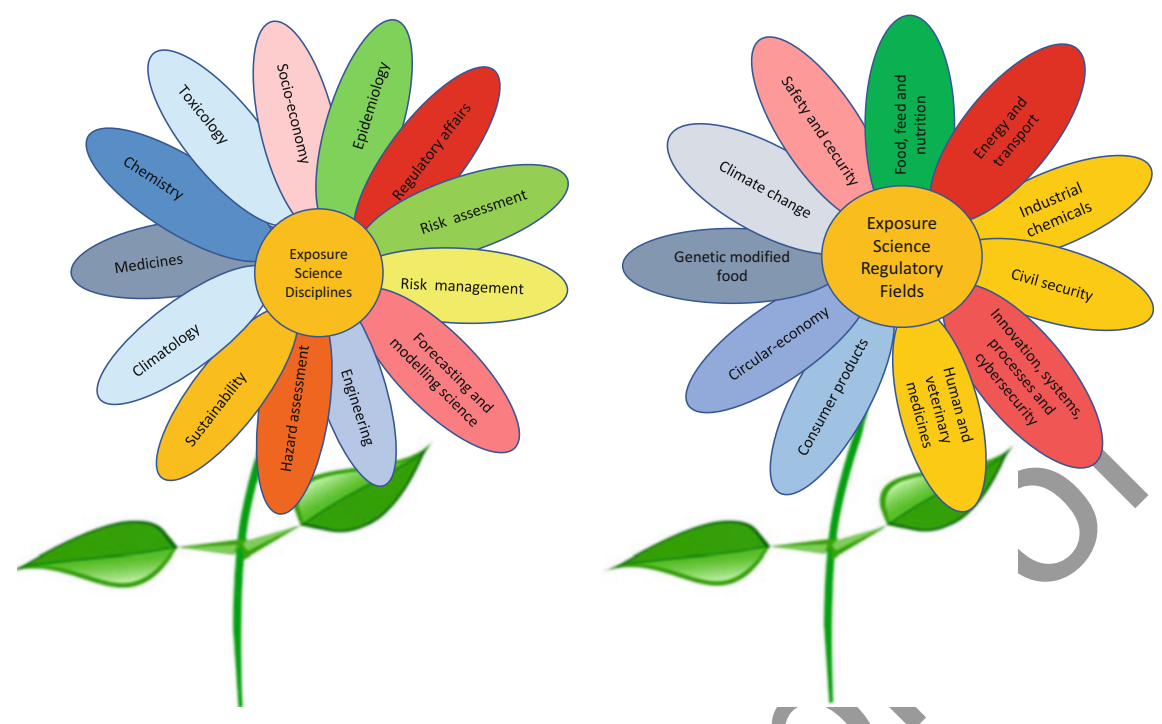

Fig. 7.6 (a) Related and overlapping disciplines that benefit from exposure science and (b) EU Regulatory domains for which exposure knowledge is crucial. Disciplines that benefit of Exposure Science

provides opportunities for career development, and acknowledges and promotes excellence in the practice of exposure assessments and research in the field of exposure science. This statement reflects ISES's dedication to promoting, protecting, and enhancing the role of exposure science in diverse fields and professional disciplines across academia, government, industry, and policy makers (https:// www.intlexposurescience. .rg).

As part of this mission, ISES aims at the advancement of exposure science related to environmental contaminants, both for human populations and ecosystems. Its objective is to foster and advance exposure science related to environmental contamination in human populations and ecosystems; promote communication among exposure analysts, epidemiologists, toxicologists, and other scientists; recommend approaches to methodological concerns; and strengthen the impact of exposure assessment and analysis on environmental policy. ISES also aims to disseminate results for the general public, workers, consumers, etc. using proper science communication instruments.

ISES stands for a knowledge society having societal relevance. It is internationally embedded and via its members methodologically innovative. ISES mission is to provide state-of-the-art science and demand-driven policy support to protect human and environmental health. To reach this mission, core values are expertise, reliability, independence, self-consciousness, purposefulness, vigilance, international mindedness, innovativeness, flexibility, partnership and entrepreneurship. The Society's multidisciplinary expertise and international reach make it the premier 
professional society for practitioners associated with all aspects of exposure science (research, teaching, policy, communication, and outreach).

\subsubsection{ISES Annual Meetings}

Over the years, the annual meeting has become the cornerstone of the Society's direct interaction with its members and the place where those interested in exposure science can meet, exchange ideas, and develop ideas for the future. At the beginning, all meetings were held in collaboration with different societies (joint meetings) because it was believed that ISES was too small to have a meeting on its own. Additionally, this approach helped to increase the Society's visibility amongst other societies and disciplines. The year 1997 marked the first time ISES had its own annual meeting. Annual meetings are now held routinely and the goal is to have a joint meeting every third year with another society. The need for ISES 'only' meetings was essential for determining how well ISES was achieving its goals and mission. In future years the Society plans to host specialty conferences devoted to particular areas of interest and new areas of concern to members and others.

\subsubsection{The International Society of Exposure Science (ISES): Regional Chapters}

The Society encourages members in different geographic regions to form regional chapters to:

- Facilitate meetings among members who reside in close proximity

- Provide guidance on local scientific, regulatory and policy issues that require an understanding of exposure to environmental or occupational agents, and

- Provide a forum for promoting student participation in the field of exposure science.

\section{North America}

Tri-State Regional Chapter (New Jersey, New York, Pennsylvania).

This Chapter's aim is to foster and advance the science of exposure analysis related to environmental contaminants, both for human populations and ecosystems, and to promote communication among scientists, regulatory personnel, general public and other individuals or organisations (http://isestristate.org/). 


\section{California Chapter}

The objectives of this Chapter are to foster and promote the goals, purposes, and objectives of the International Society of Exposure Science among scientists and at institutions within California. In particular, the objectives of the Chapter are to further understanding, awareness, and appropriate applications of exposure science, and to promote an exchange of ideas, communication and practical experiences among members of the academic, professional, industrial, and regulatory communities engaged in exposure science, e.g. exposure scientists, epidemiologists, toxicologists, and other scientists in academia, government, and industry. The Chapter aims to act as a resource for and to provide support to the Society (https:// www.isescalifornia.org/).

\section{Asia}

The East Asia Chapter is for members within the East Asian countries, like Japan, China, Taiwan, Korea, etc. The objectives of the Chapter are to: (a) foster, promote and advance the science of exposure analysis related to environmental stressors in human populations and ecosystems, (b) promote communication among scientists, policy makers, the general public and other individuals or organisations interested (items listed in the first objective), (c) strengthen the impact of exposure science on environmental policy making, (d) serve as the focal point for interaction of members of the Society and other interested individuals from academia, government and industry in the East Asian countries, i.e. to provide communication and interaction opportunities for researchers, particularly young investigators and scientists associated with government whose opportunity to travel to international meetings is limited, (e) further improve the understanding, awareness, and appropriate applications of exposure science, and to promote an exchange of ideas, communication and practical experiences among members of the academic, professional, industrial and regulatory communities engaged in exposure science, e.g. exposure scientists, epidemiologists, toxicologists and other scientists in academia, government and industry, (f) disseminate exposure information and concepts to all interested individuals, (g) foster integration and interaction of the various disciplines involved in exposure science, (h) hold scientific and educational meetings and workshops, and (i) act as a resource for and provide support to the Society.

\subsubsection{Europe}

The European Regional Chapter (further referred to as ISES-Europe) is the youngest Regional Chapter of ISES. The increasing need to have a European programme to promote increased generation of exposure information followed by independent 
Fig. 7.7 Geographical distribution of meeting participants

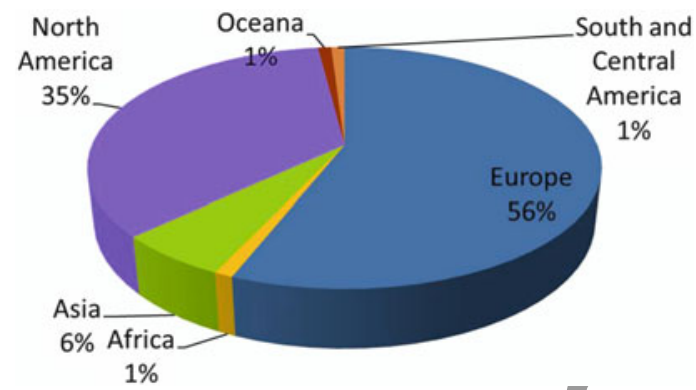

assessment and use by risk managers and policy makers was the main driver to set up the European Regional Chapter. ISES-Europe is regarded to be crucial in starting off such a programme in Europe at the moment; no other independent organisation is likely to fulfil this job. In addition, many if not all objectives of such a European programme are fully in line with the general objective of the Society as a whole. In this respect, the establishment of ISES-Europe is the first step in the strategy towards the establishment of that European programme for exposure science (http://iseseurope.org/).

The 2016 meeting in Utrecht, the Netherlands was the biggest meeting since the start of the Society with participants from 50 different countries (see Fig. 7.7).

During the 2016 annual meeting in Utrecht, efforts were made to establish ISESEurope as an answer to requests to explore this from many ISES members in Europe. Based on the input obtained, ISES-Europe was officially established in mid-2017, and elections were held to establish the ISES-Europe Board among the European members of ISES. Once established the Board endorsed the draft mission and draft bylaws as prepared before the Utrecht meeting. Subsequently and based on this, the ISES-Europe Board reflected on the definition of exposure science in Europe and came up with six key objectives.

Mission of ISES-Europe ISES-Europe's mission is to integrate exposure science into European regulations and industry practice, and to anchor it in academic research and education, in order to foster innovation and to create a safe and sustainable future for humans and the environment.

What Is Exposure Science? Exposure science in its broadest sense studies the contact between stressors (primarily chemical, biological, and physical agents) and receptors (e.g. molecules, cells, organs, humans, other living organisms, and non-living items like buildings), and the associated pathways and processes potentially leading to negative effects on human health and the natural and built environment. 


\section{ISES-Europe's Key Objectives}

1. Build a European Programme to generate, assess, exchange, and communicate experimental and model-based exposure data in support of a European strategy for exposure science in the twenty-first century

2. Advance exposure science with focus on closing knowledge gaps, building science-based and operational data and methods, fostering integration and interaction of disciplines involved in exposure science, and anchoring exposure information in decision-making by all stakeholders

3. Provide guidance and recommendations for exposure assessment in science and policy

4. Foster the inclusion of realistic exposure information in risk assessment, alternatives assessment and chemical substitution, high-throughput risk screening, life cycle assessment, and other regulatory and non-regulatory frameworks and management tools

5. Strengthen the impact of exposure science on human health and environmental policies

6. Support trans-agency and trans-institutional coordination, education, and engaging a broader European stakeholder community including triggering and supporting a European infrastructure to facilitate sharing, generation and dissemination of exposure information.

\subsubsection{An Increasing Need for International Exposure Information}

REACH, the current EU Regulation on chemicals management, created a mandate to deliver adequate exposure information to foster the safe use and management of chemicals. Exposure information is also required in other European regulatory frameworks (Endsdaily, 25/05/2016 ec.europa.eu/jrc/en/research-topic/human-expo sure, echa.europa.eu, www.efsa.europa.eu, osha.europa.eu/en) (including regulations on plant protection products (ec.europa.eu/jrc/en/research-topic/humanexposure, echa.europa.eu, www.efsa.europa.eu, osha.europa.eu/en) biocidal products (echa.europa.eu/regulations/biocidal-products-regulation/understanding-bpr), construction products (ec.europa.eu/growth/sectors/construction/product-regula tion_en), general product safety (ec.europa.eu/consumers/consumers_safety/prod uct_safety_legislation/general_product_safety_directive/index_en.htm), classification, labelling and packaging (ec.europa.eu/growth/sectors/chemicals/ classification-labelling_en), control of air quality (ec.europa.eu/environment/air/ quality/existing_leg.htm) and major accident hazards (ec.europa.eu/environment/ seveso/), etc. Current EU chemicals frameworks such as the ones listed above are complex and often in need of appropriate exposure information. Therefore, the starting focus of ISES-Europe has been on chemicals. At a later stage, physical and biological stressors may be incorporated. 
Outside the EU, several countries in or near Europe are following or have even implemented complete legislative instruments. One example of a multilateral agreement is the participation of Norway, Switzerland, Liechtenstein and Iceland in EFTA (European Free Trade Association). Also, there are bilateral agreements between a Member State and the EU. Further away, other countries have also modified their chemicals legislation. They include China, Korea, Malaysia, Russia, Taiwan and Turkey, with some of the legislation having elements similar to REACH. These developments also increase the need for adequate exposure information.

Within the European Union, notification and registration processes of chemicals by industry that include submission of confidential and non-confidential information on (foreseeable) exposures and hazards have released a huge amount of data. Many of the non-confidential data (albeit with varying degrees of uncertainty) can now be found via websites of agencies like ECHA (Search for Chemicals option on https:// echa.europa.eu/information-on-chemicals) and EFSA (e.g. OpenFoodTox, EFSA Comprehensive European Food Consumption Database https://www.efsa.europa. eu/en/data/chemical-hazards-data). As a result, these data have 'gone public' and have global value. For example, companies are now avoiding substances of very high concern (SVHCs).

Chemical safety has moved beyond the environment, health and safety departments of chemical companies. Being more and more of a real and recognized business issue, it is getting onto the radar of CEOs. It is critical that these leaders approach REACH and other chemicals legislative frameworks like a healthcare system: 'it never ends' (Chemical Watch 2016). Furthermore, EU strategies to move towards a non-toxic environment by 2050 , to strive towards a circular and bio-based economy, and to promote green and sustainable chemistry add additional challenges requiring adequate exposure information (Decision No. 1386/2013/EU). The creation of a European Programme to promote increased generation of exposure information and fit-for-purpose exposure assessment tools followed by independent assessments and use by risk managers and policy makers is the main driver for the ISES-Europe Regional Chapter.

\subsubsection{The Vision of Exposure Science in Europe}

Experience has shown that regulatory anchoring and guidance is pivotal for a proper generation of any data, be it hazard data or exposure data. If not, industrial frontrunners might pay a price if there is no immediate return on investment: it is not always clear upfront for a specific chemical whether additional data generation on top of the legally required data pays off. Thus, clear regulatory anchoring which obliges all companies where the legislation applies (and indirectly far beyond) is crucial to create a level playing field for industry. In addition, it will automatically foster awareness of the usefulness of more and better exposure knowledge. Because of this, the regulatory aspects should not be neglected, but incorporated in the mission of ISES-Europe (Fig. 7.8). 


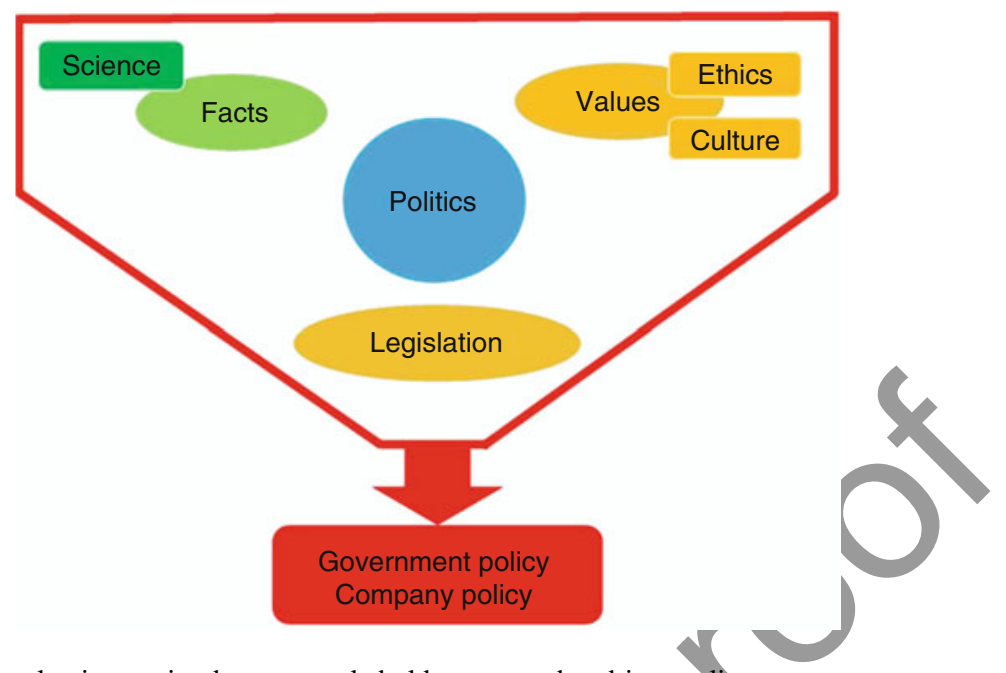

Fig. 7.8 Complex interaction between stakeholder groups that drives policy

ISES-Europe serves as an independent platform where stakeholders from society can exchange information and construct dialogues aiming at the identification of current and future scientific and policy needs and opportunities. ISES-Europe seeks to use the best dissemination strategies to ensure that needs and opportunities are communicated to relevant stakeholder groups such as academia, research funders, CEOs and competent authorities (Fig. 7.8).

ISES-Europe strives to become Europe's Reference Network on Exposure Science. One of the main tasks will be to develop a European strategy on exposure science describing ISES-Europe's vision and spelling out the exposure science activities and priorities to achieve its goals until 2030 by making a road map 2020-2025-2030. The primary focus will be to set up an overall strategy for ISES-Europe focusing on exposure-related strategic themes including a vision, mission and ambition on issues such as a European programme to: (1) assess exact and predictive exposure data; (2) enhance a better connection to Big Data and understanding its future potentials; (3) provision of a platform for more communication to explain the benefits of understanding and managing exposure to stakeholders such as academia, research institutes, national and supranational (e.g. EU) authorities and agencies, NGOs, insurance companies, industry and workers representatives, making exposure science a business case that stays within the attention of CEOs; (4) fitness check exposure science to deliver information for current policies; (5) incorporation of exposure in business strategies (not only RIE, health and safety); and (6) dealing with the socio-economic and sustainability implications of regulatory action, and more.

The ISES 2016 meeting revealed that participants representing various European stakeholders support the setting up of education and training opportunities, the development of a formal certification in Exposure Science, the creation of an exposure information exchange platform, having access to scientific networks and 
continental/regional meetings on exposure science, influencing the research and regulatory agenda and facilitating interdisciplinary collaboration and exchange. ISES-Europe is in the process of setting up its structure to build a European programme on exposure science including working groups, a European reference network on exposure science and is also in the outreach phase for engagement of stakeholders, the organisation of workshops and meetings, the setting up of a European Strategy on Exposure Sciences in 2030 with a roadmap 2020-20252030 and enlarging membership. For more information please visit: http://iseseurope.org/ and https://www.facebook.com/ISESEUROPE

\section{References}

Arcella D, Leclercq C (2005) Assessment of dietary intake of flavouring substances within the procedure for their safety evaluation: advantages and limitations of estimates obtained by means of a per capita method. Food Chem Toxicol 43:105-116

Bruinen de Bruin Y, Hakkinen P, Lahaniatis M, Papameletiou D, Del Pozo C, Reina V, van Engelen J, Heinemeyer G, Viso AC, Rodriguez C, Jantunen M (2007) Risk management measures for chemicals in consumer products: documentation, assessment, and communication across the supply chain. J Expo Sci Environ Epidemiol 17:S55-S66. http://www.nature.com/jes/ journal/v17/n1s/pdf/7500587a.pdf. Accessed 27 Oct 2019

Chemical Watch (2016) REACH-a never-ending story. https://chemicalwatch.com/46844/reacha-never-ending-story. Accessed 27 Oct 2019

EFSA (2007) Reasoned opinion on the potential chronic and acute risk to consumers health arising from proposed temporary EU MRLs. EFSA J 5(3):RN-32, 1141 pp. https://doi.org/10.2903/j. efsa.2007.32r. http://onlinelibrary.wiley.com/doi/10.2903/j.efsa.2007.32r/full. Accessed 27 Oct 2019

EFSA (2009a) Scientific opinion of the panel on food contact materials, enzymes, flavourings and processing aids (CEF) on dietary exposure assessment methods for smoke flavouring primary products. EFSA J RN-284:1-30. https://doi.org/10.2903/j.efsa.2009.248r. http://onlinelibrary. wiley.com/doi/10.2903/j.efsa.2009.248r/abstract. Accessed 27 Oct 2019

EFSA (2009b) Guidance of EFSA prepared by the scientific panel of food contact material, enzymes, flavourings and processing aids on the submission of a dossier on food enzymes. EFSA J 1305: 1-26. https://doi.org/10.2903/j.efsa.2009.1305. http://onlinelibrary.wiley.com/ doi/10.2903/j.efsa.2009.1305/full. Accessed 27 Oct 2019

EFSA (2010a) Standard sample description for food and feed. EFSA J 8(1):1457, 54 pp. https:// www.efsa.europa.eu/de/efsajournal/pub/1457. Accessed 27 Oct 2019

EFSA (2010b) Guidance on the data required for the risk assessment of flavourings to be used in or on foods. EFSA J 8(6):1623, 38 pp. https://doi.org/10.2093/j.efsa.2010.1623. http:// onlinelibrary.wiley.com/doi/10.2903/j.efsa.2010.1623/pdf. Accessed 27 Oct 2019

EFSA (2010c) The 2010 European Union Report on Pesticide residues in food. EFSA J 11(3):3130, 808 pp. https://doi.org/10.2903/j.efsa.2013.3130. http://www.efsa.europa.eu/en/efsajournal/ pub/3130. Accessed 27 Oct 2019

EFSA (2011) Use of the EFSA comprehensive European food consumption database in exposure assessment. EFSA J 9(3):2097. https://www.efsa.europa.eu/en/efsajournal/pub/2097. Accessed 27 Oct 2019

EFSA (2012a) Guidance of the FEEDAP panel for establishing the safety of additives for the consumer. EFSA J 10(1):2537, 12 pp. https://doi.org/10.2903/j.efsa.2012.2537. http:// onlinelibrary.wiley.com/doi/10.2903/j.efsa.2012.2537/abstract. Accessed 27 Oct 2019 
EFSA (2012b) Guidance for submission for food additive evaluations. EFSA J 10(7):2760. http:// onlinelibrary.wiley.com/doi/10.2903/j.efsa.2012.2760/epdf. Accessed 27 Oct 2019

EFSA (2013) Standard sample description ver. 2.0. EFSA J 11(10):3424, 114 pp. https://doi.org/10. 2903/j.efsa.2013.3424. Accessed 27 Oct 2019

EFSA (2014a) Food additives intake model (FAIM): comments received from stakeholders and EFSA's views. EFSA Support Publ 2014:EN-566, 25 pp. https://doi.org/10.2903/sp.efsa.2014. EN-566. http://onlinelibrary.wiley.com/doi/10.2903/sp.efsa.2014.EN-566/full. Accessed 27 Oct 2019

EFSA (2014b) Guidance on the EU Menu methodology. EFSA J 12(12):3944, 77 pp. https://doi. org/10.2903/j.efsa.2014.3944. http://onlinelibrary.wiley.com/doi/10.2903/j.efsa.2014.3944/ abstract. Accessed 27 Oct 2019

EFSA (2014c) Guidance on data exchange version 2.0. EFSA J 12(12):3945, $173 \mathrm{pp}$. https://doi. org/10.2903/j.efsa.2014.3945. http://onlinelibrary.wiley.com/doi/10.2903/j.efsa.2014.3945/ abstract. Accessed 27 Oct 2019

EFSA (2014d) Guidance on the assessment of exposure of operators, workers, residents and bystanders in risk assessment for plant protection products. EFSA J 2014;12(10):3874, 55 pp. https://doi.org/10.2903/j.efsa.2014.3874. http://onlinelibrary.wiley.com/doi/10.2903/j.efsa. 2014.3874/abstract. Accessed 27 Oct 2019

EFSA (2014e) Scientific Opinion on the safety assessment of carvone, considering all sources of exposure. EFSA J 12(7):3806, 74 pp. https://doi.org/10.2903/j.efsa.2014.3806. http:// onlinelibrary.wiley.com/doi/10.2903/j.efsa.2014.3806/abstract. Accessed 27 Oct 2019

EFSA (2014f) Guidance on expert knowledge elicitation in food and feed safety risk assessment. EFSA J 12(6):3734, 278 pp. https://doi.org/10.2903/j.efsa.2014.3734. http://onlinelibrary. wiley.com/doi/10.2903/j.efsa.2014.3734/abstract. Accessed 27 Oct 2019

EFSA (2015a) The EFSA Data Warehouse access rules. EFSA Support Publ 12(2):EN-768, 18 pp. https://doi.org/10.2903/sp.efsa.2015.EN-768. http://onlinelibrary.wiley.com/doi/10.2903/sp. efsa.2015.EN-768/abstract. Accessed 27 Oct 2019

EFSA (2015b) Scientific opinion of the CEF panel on the risks to public health related to the presence of bisphenol A (BPA) in foodstuffs: executive summary. EFSA J 13(1):3978, 23 pp. https://doi.org/10.2903/j.efsa.2015.3978. http://onlinelibrary.wiley.com/doi/10.2903/j.efsa. 2015.3978/abstract. Accessed 27 Oct 2019

EFSA (2016a) Corporate publication. EFSA strategy 2020. Trusted science for safe food. http:// www.efsa.europa.eu/sites/default/files/corporate_publications/files/strategy2020.pdf. Accessed 27 Oct 2019

EFSA (2016b) Exposure assessment of food enzymes. Statement of the EFSA panel on food contact materials, enzymes, flavourings and processing aids. EFSA J 14(11):4581, 9 pp. https://doi.org/ 10.2903/j.efsa.2016.4581. http://onlinelibrary.wiley.com/doi/10.2903/j.efsa.2016.4581/ abstract. Accessed 27 Oct 2019

EFSA (2016c) Scientific opinion of the CEF Panel on recent developments in the risk assessment of chemicals in food and their potential impact on the safety assessment of substances used in food contact materials. EFSA J 14(1):4357, 28 pp. https://doi.org/10.2903/j.efsa.2016.4357. http:// onlinelibrary.wiley.com/doi/10.2903/j.efsa.2016.4357/abstract. Accessed 27 Oct 2019

EFSA (2016d) Guidance of the NDA panel on the preparation and presentation of an application for authorisation of a novel food in the context of Regulation (EU) 2015/2283. EFSA J 14 (11):4594, 24 pp. https://doi.org/10.2903/j.efsa.2016.4594. http://onlinelibrary.wiley.com/doi/ 10.2903/j.efsa.2016.4594/full. Accessed 27 Oct 2019

EFSA (2017a) Guidance on the use of the weight of evidence approach in scientific assessments. EFSA J 15(8):4971, 69 pp. https://doi.org/10.2903/j.efsa.2017.4971. https://www.efsa.europa. eu/en/efsajournal/pub/4971. Accessed 27 Oct 2019

EFSA (2017b) Guidance on the assessment of the safety of feed additives for the consumer. EFSA J 15(10):5022, 17 pp. https://doi.org/10.2903/j.efsa.2017.5022. http://onlinelibrary.wiley.com/ doi/10.2903/j.efsa.2017.5022/full. Accessed 27 Oct 2019 
EFSA (2018) Guidance on uncertainty analysis in scientific assessments. EFSA J 16(1):5123, 39 pp. https://doi.org/10.2903/j.efsa.2018.5123. http://onlinelibrary.wiley.com/doi/10.2903/j. efsa.2018.5122/abstract. Accessed 27 Oct 2019

ENDS Europe DAILY (2016) ECHA calls for stricter chemicals registration rules. (27/05/2016) https://echa.europa.eu/news-and-events/news-ale. Accessed 27 Oct 2019

EU (1991) Council Directive 91/414/EEC of 15 July 1991 concerning the placing of plant protection products on the market. http://eur-lex.europa.eu/legal-content/EN/TXT/?uri=celex \%3A31991L0414. Accessed 27 Oct 2019

EU (2001) Regulation (EC) No 1049/2001 of the European Parliament and of the Council of 30 May 2001 regarding public access to European Parliament, Council and Commission documents. http://eur-lex.europa.eu/legal-content/EN/TXT/HTML/?uri=LEGISSUM: $114546 \&$ from $=$ EN. Accessed 27 Oct 2019

EU (2002) Regulation (EC) No 178/2002 of the European Parliament and of the Council of 28 January 2002 laying down the general principles and requirements of food law, establishing the European Food Safety Authority and laying down procedures in matters of food safety. OJ (L31):1-24. 1.2.2002. http://eur-lex.europa.eu/legal-content/EN/TXT/HTML/? uri=CELEX:32002R0178\&from=EN. Accessed 27 Oct 2019

EU (2005) Regulation (EC) No 396/2005 of the European Parliament and of the Council of 23 February 2005 on maximum residue levels of pesticides in or on food and feed of plant and animal origin and amending Council Directive 91/414/EE. http://eur-lex.europa.eu/legalcontent/EN/TXT/HTML/?uri=CELEX:32005R0396\&from=en. Accessed 27 Oct 2019

EU (2009) Regulation (EC) No 1107/2009 of the European Parliament and of the Council of 21 October 2009 concerning the placing of plant protection products on the market and repealing Council Directives 79/117/EEC and 91/414/EEC http://eur-lex.europa.eu/legal-con tent/EN/TXT/?uri=CELEX:32009R1107. Accessed 27 Oct 2019

EU (2010) Commission Decision of 16 December 2009 laying down guidelines for the management of the Community Rapid Information System 'RAPEX' established under Article 12 and of the notification procedure established under Article 11 of Directive 2001/95/EC (the General Product Safety Directive). Off J Eur Union 53(L22):1-64, 26 January 2010. Accessed 27 Oct 2019

EU (2013) Commission Implementing Regulation (EU) No 503/2013 of 3 April 2013 on applications for authorisation of genetically modified food and feed in accordance with Regulation (EC) No 1829/2003 of the European Parliament and of the Council and amending Commission Regulations (EC) No 641/2004 and (EC) No 1981/2006 (1)

EU (2019) Regulation (EU) No 2019/1381 of the European Parliament and of the Council of 20 June 2019 on the transparency and sustainability of the EU risk assessment in the food chain and amending Regulations (EC) No 178/2002, (EC) No 1829/2003, (EC) No 1831/2003, (EC) No 2065/2003, (EC) No 1935/2004, (EC) No 1331/2008, (EC) No 1107/2009, (EU) 2015/2283 and Directive 2001/18/EC. https://eur-lex.europa.eu/legal-content/EN/TXT/?uri=uriserv:OJ.L_. 2019.231.01.0001.01.ENG\&toc=OJ:L:2019:231:TOC. Accessed 28 Oct 2019

Fagt S, Matthiessen J, Trolle E, Lyhne N, Christensen T, Hinsch HJ, Hartkopp H, Biltoft-Jensen A, Møller A, Daae AS (2002) [Dietary habits in Denmark 2000-2001: developments in dietary consumption, purchases and habits in Denmark] Danskernes kostvaner 2000-2001: Udviklingen i danskernes kost-forbrug, indkøb og vaner, Danish food directorate, Department of nutrition, Food Report 2002, 10, June 2002, ISBN 87-91189-37-3. http://www.food.dtu. dk/-/media/Institutter/Foedevareinstituttet/Publikationer/Pub-2002/Danskernes-kostvaner2000-2001.ashx?la=da

Heinemeyer G, van Engelen J, Papameletiou D (2006) Consumer exposure scenarios under reach. Epidemiology 17(6):S63. Abstract. http://journals.lww.com/epidem/Fulltext/2006/11001/Con sumer_Exposure_Scenarios_Under_Reach.135.aspx?trendmd-shared $=0$. Accessed 27 Oct 2019

Meek ME, Boobis AR, Crofton KE, Heinemeyer G, Van Raaij M, Vickers C (2011) Risk assessment of combined exposure to multiple chemicals: a WHO/IPCS framework. Regul 
Toxicol Pharmacol 60(2011):S1-S14. https://doi.org/10.1016/j.yrtph.2011.03.010. https:// www.ncbi.nlm.nih.gov/pubmed/21466831

NRC (2012) Exposure science in the 21st century. A vision and a strategy. National Academies Press, Washington, DC. isbn:978-0-309-26468-6

OECD (2003) Guidance document on reporting summary information on environmental, occupational and consumer exposure. Environment, Health and Safety Publications, Series on testing and assessment no. 42. ENV/JM/MONO(2003)16. http://www.oecd.org/officialdocuments/ publicdisplaydocumentpdf $/$ ?cote $=\mathrm{env} / \mathrm{jm} / \mathrm{mono}(2003) 16 \&$ doclanguage $=\mathrm{en}$. Accessed 27 Oct 2019

OECD (2009) Emission scenario document on plastic additives. Environment, Health and Safety Publications, Series on Emission Scenario Documents No. 3. ENV/JM/MONO(2004)8/REV1. http://www.oecd.org/officialdocuments/publicdisplaydocumentpdf/?cote=env/jm/mono(2004) 8/rev1\&doclanguage $=$ en. Accessed 27 Oct 2019

OECD (2011a) WHO OECD ILSI/HESI international workshop on risk assessment of combined exposures to multiple chemicals: workshop report. Environment, Health and Safety Publications, Series on Testing and Assessment No. 140. ENV/JM/MONO(2011)103. http://www. oecd.org/officialdocuments/publicdisplaydocumentpdf/?cote $=$ env/jm/mono(2011) $10 \&$ doclanguage $=$ en. Accessed 27 Oct 2019

OECD (2011b) WHO OECD ILSI/HESI international workshop on risk assessment of combined exposures to multiple chemicals: annex 2. Environment, Health and Safety Publications, Series on testing and assessment no. 140. ENV/JM/MONO(2011)10/ANN2. http://www.oecd.org/ officialdocuments/publicdisplaydocumentpdf/?cote=env/jm/mono(2011)10/ann2\& doclanguage $=$ en. Accessed 27 Oct 2019

OECD (2011c) WHO OECD ILSI/HESI international workshop on risk assessment of combined exposures to multiple chemicals: annex 3. Environment, Health and Safety Publications, Series on testing and assessment no. 140. ENV/JM/MONO(2011)10/ANN3. http://www.oecd.org/ officialdocuments/publicdisplaydocumentpdf/?cote $=$ env/jm/mono(2011)10/ann3\& doclanguage $=$ en. Accessed 27 Oct 2019

OECD (2011d) WHO OECD ILSI/HESI international workshop on risk assessment of combined exposures to multiple chemicals: annex 7. Environment, Health and Safety Publications, Series on testing and assessment no. 140. ENV/JM/MONO(2011)10/ANN7. http://www.oecd.org/ officialdocuments/publicdisplaydocumentpdf/?cote $=$ env/jm/mono(2011)10/ann7\& doclanguage $=$ en. Accessed 27 Oct 2019

OECD (2013a) Guidance document for exposure assessment based on environmental monitoring. Environment, Health and Safety Publications, Series on testing and assessment no. 185. ENV/JM/MONO(2013)7. http://www.oecd.org/officialdocuments/publicdisplaydocumentpdf/? cote $=$ env/jm/mono(2013) $7 \&$ doclanguage $=$ en. Accessed 27 Oct 2019

OECD (2013b) Descriptions of existing models and tools used for exposure assessment-results of OECD survey. Environment, Health and Safety Publications, Series on testing and assessment no. 182. ENV/JM/MONO(2012)37. http://www.oecd.org/officialdocuments/ publicdisplaydocumentpdf $/$ ? cote $=$ env/jm/mono(2012) $37 \&$ doclanguage $=e n$. Accessed 27 Oct 2019

OECD (2016) Harmonised templates 301 to 306: use and exposure information. http://www.oecd. org/ehs/templates/harmonised-templates-use-exposure-information.htm. Accessed 27 Oct 2019

OECD (2018) Considerations for assessing the risks of combined exposure to multiple chemicals. Series on testing and assessment no. 296, Environment, Health and Safety Division, Environment Directorate. ENV/JM/MONO(2018)37. http://www.oecd.org/chemicalsafety/risk-assess ment/considerations-for-assessing-the-risks-of-combined-exposure-to-multiple-chemicals.pdf. Accessed 27 Oct 2019

Phillips L, Johnson M, Deener K, Bonanni C (2015) EPA's exposure assessment toolbox (EPA-Expo-Box). J Environ Inf 25(2):81-84. https://doi.org/10.3808/jei.201400269

Turrini A, Saba A, Perrone D, Cialfa E, D'Amicis A (2001) Food consumption patterns in Italy: the INN-CA Study 1994-1996. Eur J Clin Nutr 55(7):571-588 
van Engelen JGM, Heinemeyer G, Rodriguez C (2007) Consumer exposure scenarios: development, challenges and possible solutions. J Expo Sci Environ Epidemiol 17:S26-S33. http:// www.nature.com/jes/journal/v17/n1s/pdf/7500577a.pdf

van Leeuwen CJ, Vermeire TG (2007) Risk assessment of chemicals: an introduction, 2nd edn. Springer, Cham. isbn:978-1-4020-6101-1

Vermeire T, Bruinen de Bruin Y, Traas T, Bolte J, van Engelen J, Evers E, Herremans J, Hogerwerf L, van der Linden T, Ossendorp B, Peijnenburg W, Piersma A, Schols E, Sijm D, Tielemans E, Traas T, van der Vliet D, Dissel S, Lebret E (2017) RIVM exposure assessment strategy 2016-2020 (internal paper)

Vuori V, Zaleski RT, Jantunen MJ (2006) ExpoFacts-an overview of European exposure factors data. Risk Anal 26(3):831-843. https://doi.org/10.1111/j.1539-6924.2006.00772.x

WHO (2004) IPCS risk assessment terminology. IPCS harmonization project document no. 1. WHO, Geneva. isbn:92 4156267 6. http://www.who.int/ipcs/methods/harmonization/ areas/terminology/en/. Accessed 27 Oct 2019

WHO (2005) Principles of characterizing and applying human exposure models. IPCS harmonization project document no. 3, WHO, Geneva. isbn:92 4 156311.7. http://www.who.int/ipcs/ publications/methods/harmonization/en/. Accessed 27 Oct 2019

WHO (2008) Uncertainty and data quality in exposure assessment. Part 1: guidance document on characterizing and communicating uncertainty in exposure assessment. IPCS harmonization project document no. 6. WHO, Geneva. isbn:978 9241563765 http://www.who.int/ipcs/ publications/methods/harmonization/en/. Accessed 27 Oct 2019

WHO OECD ILSI/HESI (2011) Report of the international workshop on risk assessment of combined exposures to multiple chemicals: annex 2. Environment, Health and Safety Publications, Series on testing and assessment no. 140, ENV/JM/MONO(2011)10/ANNEX 2, 15-16 Feb 2011, Paris. http://www.oecd.org/officialdocuments/publicdisplaydocumentpdf/?cote= ENV/JM/MONO(2011)10/ANN2\&docLanguage=En. Accessed 27 Oct 2019

Zaleski RT, Gephart L (2001) Exposure factors sourcebook for European populations (with focus on UK data). Technical report no. 79. European Centre for Ecotoxicology and Toxicology of Chemicals (ECETOC)

Zaleski RT, Egeghy PP, Hakkinen PJ (2016) Exploring global exposure factors resources for use in consumer exposure assessments. Int J Environ Res Public Health 13(7):744. https://doi.org/10. 3390/ijerph13070744

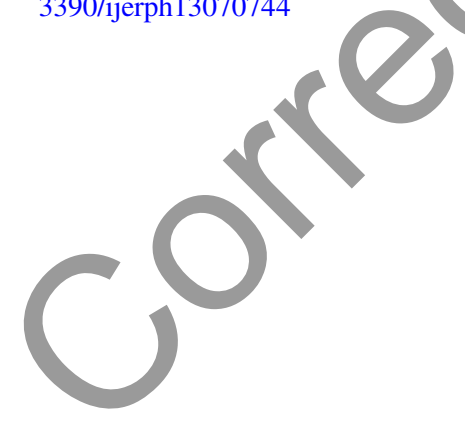

